Universidade de São Paulo

Faculdade de Medicina de Ribeirão Preto

Razão da força muscular e eletromiográfica dos

músculos extensores e flexores cervicais em

indivíduos com migrânea - um estudo transversal
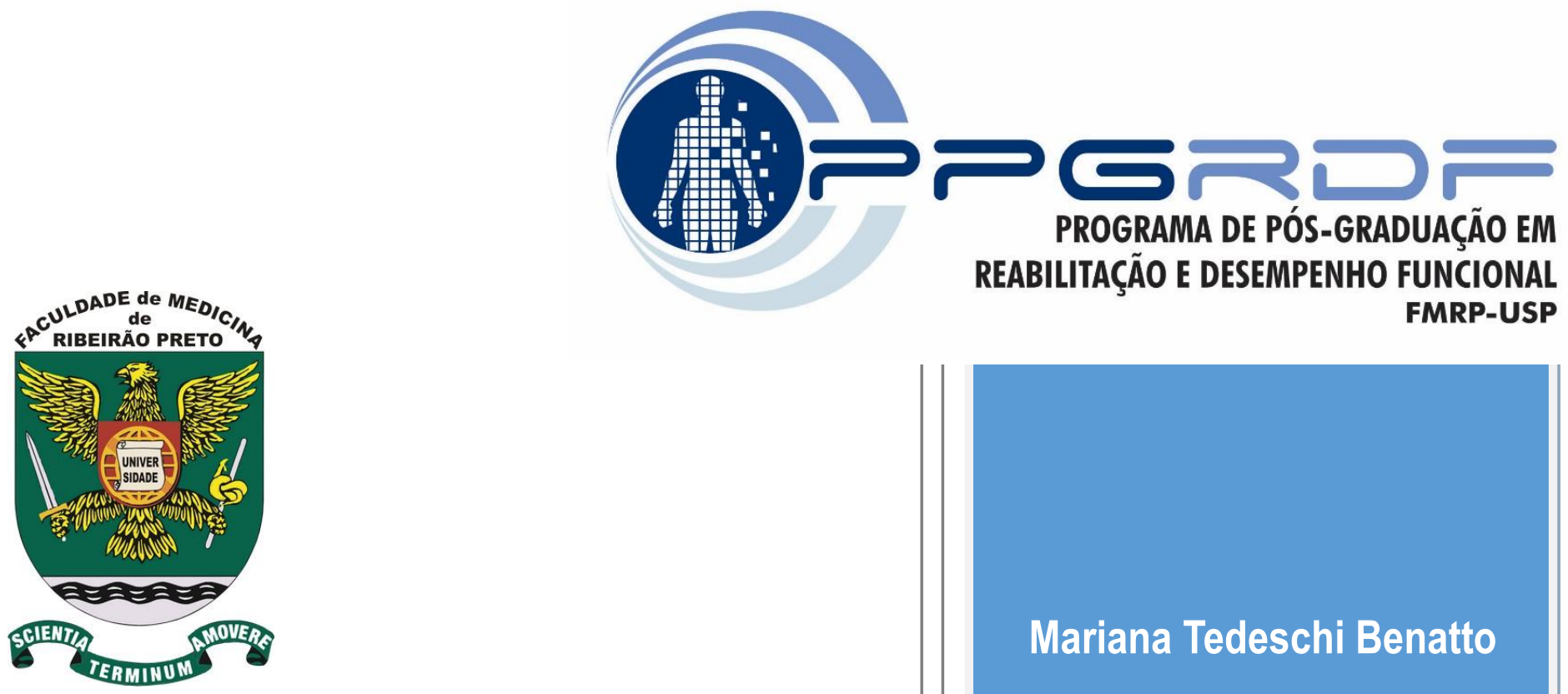

Mariana Tedeschi Benatto

Dissertação 


\section{Razão da força muscular e eletromiográfica dos músculos extensores e flexores cervicais em indivíduos com migrânea - um estudo transversal.}

\section{Versão corrigida}

Dissertação apresentada à Faculdade de Medicina de Ribeirão Preto da Universidade de São Paulo para obtenção do título de Mestre em Ciências.

Área de concentração: Fisioterapia

Orientadora: Profa. Dra. Débora Bevilaqua-Grossi

Colaboradores: Dra. Lidiane Lima Florencio e Profa. Dra. Fabíola Dach 
Autorizo a reprodução e divulgação total ou parcial deste trabalho, por qualquer meio convencional ou eletrônico, para fins de estudo e pesquisa, desde que citada a fonte.

Catalogação da Publicação

Faculdade de Medicina de Ribeirão Preto da Universidade de São Paulo

Benatto, Mariana Tedeschi

Razão da força muscular e eletromiográfica dos músculos extensores e flexores cervicais em indivíduos com migrânea - um estudo transversal. Ribeirão Preto, 2018.

p.59: il.8.

Dissertação apresentada à Faculdade de Medicina de Ribeirão Preto/USP - Programa de PósGraduação em Reabilitação e Desempenho Funcional, Área: Fisioterapia.

Orientadora: Bevilaqua Grossi, Débora

1. Transtornos de enxaqueca. 2. Eletromiografia. 3.Cervicalgia. 


\section{FOLHA DE APROVAÇÃO}

Nome: BENATTO, Mariana Tedeschi

Título: Razão da força muscular e eletromiográfica dos músculos extensores e flexores cervicais em indivíduos com migrânea - um estudo transversal.

Dissertação apresentada à Faculdade de Medicina de Ribeirão Preto da Universidade de São Paulo junto ao Departamento de Ciências da Saúde para obtenção do título de Mestre em Ciências pelo Programa de PósGraduação em Reabilitação e Desempenho Funcional. Área: Fisioterapia.

Aprovada em: 26/10/2018.

\section{BANCA EXAMINADORA}

Professor Dr. Carlos Fernando Pereira da Silva Herrero

Instituição: Faculdade de Medicina de Ribeirão Preto da Universidade de São Paulo Assinatura:

Professor Dr. Renato de Moraes

Instituição: Escola de Educação Física e Esporte de Ribeirão Preto da Universidade de São Paulo

Assinatura:

Professora Dra. Ana Beatriz de Oliveira

Instituição: Universidade Federal de São Carlos

Assinatura: 
Dedico com todo o meu coração aos meus pais, João Carlos e Maristela, ao meu irmão Guilherme e ao meu futuro marido Paulo, os quais são minha fonte inesgotável de força e perseverança. Sem o incentivo e apoio de cada um, nada seria possível. 


\section{Agradecimentos}

Inicialmente, agradeço a Deus e a Nossa Senhora do Carmo, aos quais, por inúmeras vezes recorri, para que acalmassem meu coração e guiassem meus passos. Durante o trilhar desse caminho, tive a feliz oportunidade de conhecer a majestosa igreja de Nossa Senhora do Carmo em Tiradentes- MG durante um congresso. Ao entrar, senti-me abençoada e amparada. Ao sair, tive a certeza de que cada esforço valeria a pena e de que sempre estaria protegida.

Nesse momento, gostaria de agradecer minha orientadora, Professora Débora, por me dar a oportunidade de aprender e crescer entre gigantes. Nossa história começou logo nos meus primeiros anos de faculdade e, felizmente, mantém-se até hoje. Digo que a semente da "cefaleia" foi plantada em meu coração e mesmo durante as curvas do caminho, ela floriu e espero que dê muitos frutos. Sem muitas delongas, agradeço à senhora com todo o meu amor por todo o apoio e dedicação, como orientadora e como pessoa, e por me permitir crescer, acadêmica e pessoalmente.

Ainda falando sobre pessoas que fazem diferença em nossas vidas, não poderia deixar de agradecer a veterana e colaborada Lidiane. Nosso contato começou quando eu era apenas uma aluna de iniciação científica e havia iniciado minhas atividades no laboratório. A fama dela não era das melhores, os alunos tinham "medo" e diziam que ela era muito exigente e rígida. $\mathrm{Eu}$, ao contrário, nunca tive essa visão e para mim, ela sempre foi como uma irmã mais velha que sempre me ajudava, mas que também “puxava minha orelha” nas horas necessárias. De todo o meu coração, Lidi, obrigada por todo o suporte durante todos esses anos. Saiba que fará muita falta! Mas saiba também que estará no lugar onde sempre mereceu estar.

Agradeço a todos os amigos e companheiros do LAPOMH os quais são inúmeros e com receio de me esquecer de alguém, opto por não citar ninguém. Entretanto, mesmo sem citar nomes, gostaria de registrar meu sincero obrigada pelo companheirismo e troca de experiências.

Agradeço à FAPESP pelo apoio financeiro, o qual foi essencial e tornou possível a realização desse trabalho, ao Tenysson Will pelo suporte técnico com os equipamentos e softwares e à amiga Marcela, pelo auxílio inigualável durante as coletas e organização dos dados, além do apoio pessoal com suas conversas e conselhos. Não poderia deixar de agradecer ainda as amigas Nicoly e Juliana que chegaram depois, mas ocupam um lugar especial no meu coração e tornam o dia-a-dia no laboratório mais iluminado e cheio de paz. 
Há aqueles que estão longe fisicamente, mas bem próximos na alma. Entre os amigos de Piracicaba, em especial, gostaria de agradecer a amiga de infância Gabriella. Nos conhecemos na primeira série do ensino fundamental e desde então nunca mais nos separamos. Obrigada pelas mensagens de conforto e ânimo, pelo amor e carinho. Obrigada pela vida compartilhada e pela amizade verdadeira.

Além do crescimento profissional, Ribeirão Preto trouxe pessoas iluminadas para a minha vida. Agradeço aos amigos Amanda, Marcela F., Marcos, Ana Carolina (Guarani), Thaís e Heloísa por toda a positividade, companheirismo e carinho.

Meus pais sempre me deram liberdade para que eu fizesse as minhas escolhas. Sempre me senti muito amada e segura, pois sabia que eles me apoiariam. Se hoje posso escrever uma página inteira de agradecimentos é graças a vocês, pai e mãe, que permitiram que eu percorresse toda essa linda (e árdua) trajetória. Segundo o espiritismo, antes de encarnarmos, conhecemos os nossos "pais" e decidimos se iremos querer ou não nascer naquela família. Digo que de todas as escolhas que eu fiz, essa foi a mais certa! Não consigo encontrar palavras para agradecer tudo que fizeram e fazem por mim, pelo meu irmão e por toda a nossa família.

E por fim, agradeço aquele que acredita em todo o meu potencial quando nem eu mesma acredito. Aquele que apoia todas as minhas escolhas, por mais egoístas que elas pareçam. Aquele que sente um orgulho enorme das minhas pequenas conquistas. Durante quase 7 anos de relacionamento aprendi amar e ser amada. Compreendi o significado da palavra união. Entendi que existem pessoas de luz que entram em nossas vidas para transformar e transbordar. Você com certeza é uma delas. Com todo o meu amor agradeço a você, meu noivo e futuro marido, Paulo. 
“Feliz aquele que transfere o que sabe e aprende o que ensina".

Cora Coralina 


\section{Resumo}

BENATTO, Mariana Tedeschi. Razão da força muscular e eletromiográfica dos músculos extensores e flexores cervicais em indivíduos com migrânea - um estudo transversal [dissertação]. Ribeirão Preto: Universidade de São Paulo, Faculdade de Medicina de Ribeirão Preto, 2018. 59p.

Objetivo: verificar a razão extensores/flexores dos músculos cervicais no âmbito de força muscular e atividade eletromiográfica durante a mensuração da força na contração isométrica voluntária máxima (CIVM) e teste de flexão craniocervical (TFCC) em pacientes com migrânea e em indivíduos sem cefaleia. Além de verificar o desempenho muscular, avaliado pelo TFCC, em ambos os grupos. Materiais e métodos: foram incluídas 52 mulheres com diagnóstico de migrânea segundo a Classificação Internacional de Cefaleias e 52 mulheres sem histórico de cefaleia ou dor cervical com idade entre 18 e 55 anos. No grupo migrânea os questionários Neck Disability Index, Migraine Disability Assessment e 12-item Allodynia Symptom Checklist foram aplicados. Em ambos os grupos a força dos músculos flexores e extensores cervicais foi avaliada utilizando-se um dinamômetro manual (Lafayette Instrument Company ${ }^{\circledR}$, Lafayette, $I N, U S A)$. A CIVM foi mantida por 3 segundos e foram realizadas 3 repetições. Além do teste de força, o TFCC também foi realizado para os dois grupos utilizando-se o dispositivo de pressão Stabilizer Pressure Biofeedback ${ }^{\circledR}$ (Chatanooga, Hixson, TN, USA). O dispositivo, incialmente, foi inflado a $20 \mathrm{mmHg}$ e a participante deveria aumentar $2 \mathrm{mmHg}$ a cada estágio, totalizando cinco estágios (30 mmHg), e manter a pressão por 10 segundos. Em ambos os testes, para os dois grupos, a atividade eletromiográfica dos músculos cervicais foi avaliada por meio de sensores de superfície sem fio (Trigno ${ }^{T M}$ Wireless System, Delsys Inc. Boston, MA). Resultados: observamos que o grupo migrânea apresenta uma redução na força dos músculos flexores em comparação ao grupo controle e consequentemente, uma maior razão de força dos músculos extensores/flexores além de uma reduzida razão eletromiográfica dos músculos extensores/flexores durante a CIVM em flexão. Nossos resultados demonstraram ainda uma pior performance no TFCC no grupo migrânea e consequente aumento da razão eletromiográfica dos músculos extensores/flexores cervicais no último estágio do teste. Conclusão: de acordo com os nossos resultados podemos concluir que mulheres com migrânea apresentam um notável desequilíbrio dos músculos flexores e extensores cervicais em comparação a controles não apenas na produção de força, mas também na atividade muscular.

Palavras-chave: Transtornos de enxaqueca. Eletromiografia. Cervicalgia. 


\begin{abstract}
BENATTO, Mariana Tedeschi. Extensor/flexor ratio of neck muscle strength and electromyographic activity of individuals with migraine - a cross-sectional study [dissertation]. Ribeirão Preto: University of São Paulo, Ribeirão Preto Medical Scholl, 2018. 59p.

Objective: To verify the extensor/flexor ratio of neck muscle strength and electromyographic activity at maximal voluntary isometric contraction (MVIC) and at the craniocervical flexion test (CCFT) of patients with migraine and of individuals with no history of headache. In addition, we aimed to assess the performance of both groups at the CCFT. Materials and methods: Fifty-two women with a diagnosis of migraine according to the International Classification of Headache Disorders and 52 women without history of migraine or cervical pain with ages between 18 and 55 years were included. The Neck Disability Index, Migraine Disability Assessment and 12-item Allodynia Symptom Checklist questionnaires were applied to the migraine group. In both groups, cervical muscle strength was assessed during a MVIC using a hand-held dynamometer (Lafayette Instrument Company ${ }^{\circledR}$, Lafayette, IN, USA). The MVCI was maintained for 3 seconds and 3 repetitions were performed. The CCFT was also performed by the two groups using the Stabilizer Pressure Biofeedback ${ }^{\circledR}$ (Chatanooga, Hixson, TN, USA). The device was initially inflated to $20 \mathrm{mmHg}$ and the participant had to increase 2 $\mathrm{mmHg}$ at each stage, achieving five stages $(30 \mathrm{mmHg})$, and maintaining the pressure for 10 seconds. In both tests, the electromyographic activity of the cervical muscles was evaluated using wireless surface sensors (Trigno ${ }^{\mathrm{TM}}$ Wireless System, Delsys Inc. Boston, MA). Results: migraine group has a reduction in flexor muscle strength compared to the control group and consequently a greater muscle strength ratio of extensor/flexor and a reduced electromyographic ratio of the extensor/flexor muscles during MVIC in flexion. Our results also demonstrated a worse performance in the CCFT in the migraine group and consequent increase in the electromyographic ratio of the extensor/flexor neck muscles in the last stage of the test. Conclusion: women with migraine present a remarkable imbalance of the flexor and extensors cervical muscles compared to controls not only in the production of strength but also in muscle activity.
\end{abstract}

Keywords: Migraine Disorders. Electromyography. Neck Pain. 


\section{Lista de Figuras}

Figura 1. Fluxograma de pacientes do grupo migrânea. .................................................... 21

Figura 2. Fluxograma de voluntárias do grupo controle. ................................................... 22

Figura 3. Posicionamento da paciente durante a mensuração da força dos músculos flexores

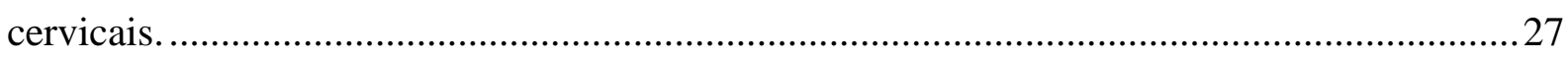

Figura 4. Posicionamento da paciente durante a mensuração da força dos músculos extensores cervicais. 27

Figura 5. Posicionamento da paciente durante o TFCC e dispositivo de suporte para a visualização da pressão.

Figura 6. Distribuição dos grupos migrânea e controle durante o TFCC 35

Figura 7. Distribuição dos valores médios do RMS normalizado e logaritmizado durante os cinco estágios do TFCC para os músculos flexores nos grupos migrânea e controle. 36

Figura 8. Distribuição dos valores médios do RMS normalizado e logaritmizado durante os cinco estágios do TFCC para os músculos extensores em ambos os grupos, migrânea e controle. 


\section{Lista de tabelas}

Tabela 1. Descrição das características da migrânea. 31

Tabela 2. Dados da força dos músculos cervicais no grupo migrânea e controle e a razão da força dos músculos extensores/flexores.

Tabela 3. Amplitude do RMS normalizado dos músculos flexores e extensores cervicais durante a CIVM. 33

Tabela 4. Razão eletromiográfica dos músculos extensores/flexores na CIVM. 34

Tabela 5. Razão eletromiográfica dos músculos extensores/flexores cervicais nos cinco estágios do TFCC nos grupos migrânea e controle. 38 


\section{Lista de abreviaturas e siglas}

ACEF - HCFMRP/USP: Ambulatório de Cefaleia e Algias Craniofaciais do Hospital das Clínicas da Faculdade de Medicina de Ribeirão Preto da Universidade de São Paulo ANCOVA: análise de covariância

ASC-12/Brasil: 12-item Allodynia Symptom Checklist/Brazil

CIC-III: Classificação Internacional de Cefaleias, $3^{\mathrm{a}}$ ed

CIVM: contração isométrica voluntária máxima

DP: desvio padrão

EA: músculo escaleno anterior

EC: músculo esplênio da cabeça

ECOM: músculo esternocleidomastóideo

EMG: eletromiografia

END: escala numérica de dor

EX/FL: razão dos músculos extensores pelos músculos flexores

FAPESP: Fundação de Amparo à Pesquisa do Estado de São Paulo

FMRP/USP: Faculdade de Medicina de Ribeirão Preto da Universidade de São Paulo

kgf: quilograma-força

MIDAS: Migraine Disability Assessment

$\mathrm{N}$ : newton

NA: não se aplica

NDI: Neck Disability Index

RMS: root mean square

TCLE: Termo de Consentimento Livre e Esclarecido

TFCC: teste de flexão craniocervical 
TS: músculo trapézio superior

$\mu \mathrm{V}$ : microvolts. 


\section{Sumário}

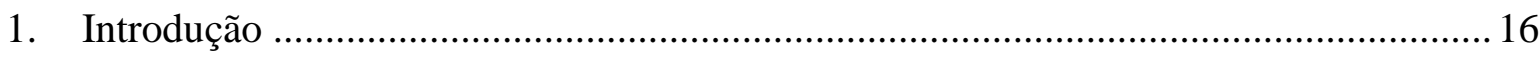

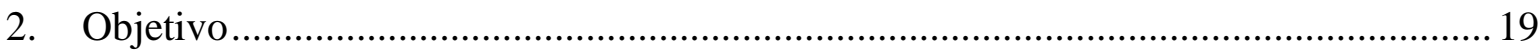

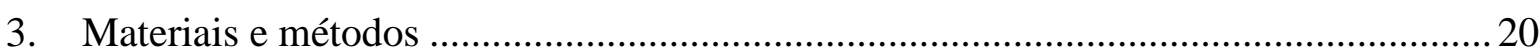

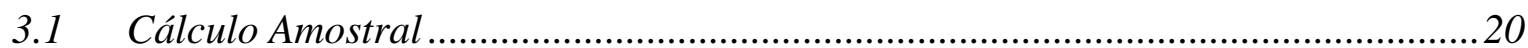

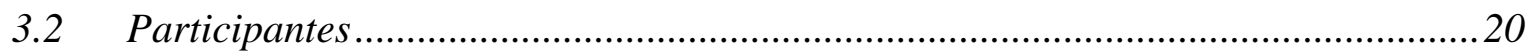

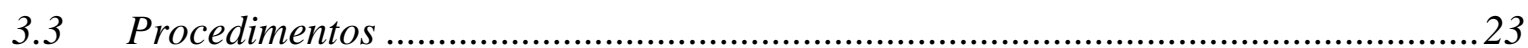

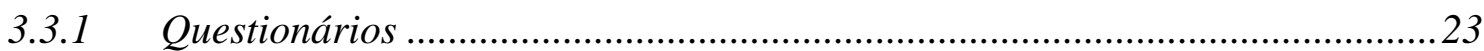

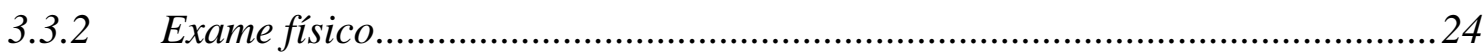

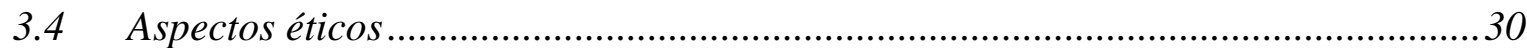

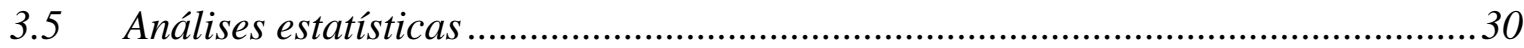

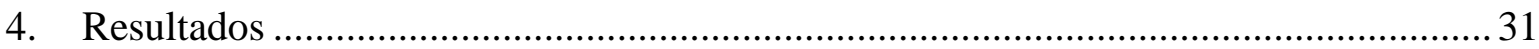

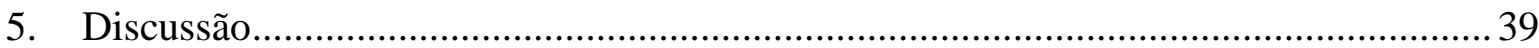

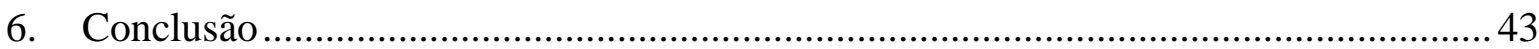

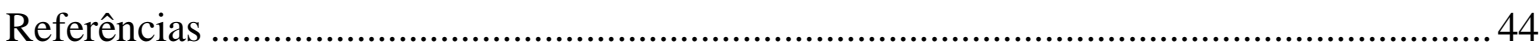

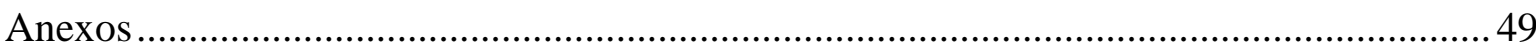

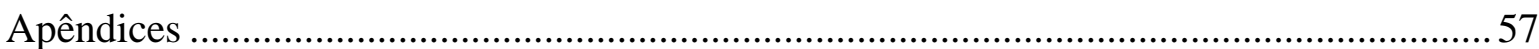




\section{Introdução}

A migrânea é entendida como uma doença neurobiológica ${ }^{1}$ e crônica ${ }^{2}$ que afeta aproximadamente $12 \%$ da população mundial adulta ${ }^{3}$ e apresenta uma prevalência anual de $17 \%$ em mulheres e $6 \%$ em homens. ${ }^{4}$ É uma das doenças mais incapacitantes em todo o mundo, ${ }^{5}$ classificada como a segunda entre as condições neurológicas, ${ }^{6}$ e suas crises são caracterizadas por perturbações recorrentes com duração de 4 a 72 horas. $^{7}$ Os sintomas comuns são: localização unilateral, caráter pulsátil, intensidade moderada ou severa, agravamento por atividade física de rotina e associada à náuseas e/ou fotofobia e fonofobia. $^{7}$

A dor no pescoço é o principal sintoma da disfunção da coluna cervical, que por sua vez é definida como um conjunto de desordens das estruturas musculoesqueléticas da região cervical, ${ }^{8}$ e assim como a migrânea, gera impacto na qualidade de vida dos indivíduos e está associada a questões socioeconômicas. ${ }^{7,9,10}$ Sabe-se que a dor cervical reflete mudanças musculoesqueléticas em indivíduos com migrânea ${ }^{11}$ e que a mesma é mais frequente do que náusea e vômito, ${ }^{7}$ não sendo simplesmente um sintoma das crises de migrânea. ${ }^{11}$ Além disso, a dor cervical é mais reportada por indivíduos com migranosos em comparação àqueles sem migrânea e pode ser um fator de risco para a cronificação da doença. ${ }^{12,13}$

Uma possível explicação para a relação entre migrânea e dor no pescoço é o complexo trigeminocervical, região anatômica na qual ocorre a convergência aferente do nervo trigêmeo e das raízes nervosas da cervical alta (C1-C3). ${ }^{14-16}$ Por meio desta aferência, é possível o relato de dor simultaneamente em áreas inervadas pelas raízes cervicais altas, como região occipital e auricular, e pelo nervo trigêmeo, como frontal, parietal e orbicular, ${ }^{17}$ possibilitando assim, a percepção de dor na cabeça ou face com origem cervical ou ainda, dor cervical com origem na cabeça.

Está estabelecido que indivíduos com dor no pescoço apresentam redução da força e da resistência dos músculos flexores ${ }^{18-20}$ e dificuldade para relaxar os músculos extensores da coluna cervical, gerando um consequente aumento da coativação desses músculos antagonistas, ${ }^{21-24}$ além de aumento da fadiga dos músculos cervicais observada por meio de análises eletromiográficas. ${ }^{25-28}$ Confirmando tais achados, Rezasoltani et al ${ }^{29}$ encontraram uma redução significativa da força isométrica de flexores e extensores da 
cervical e na razão flexores/extensores em indivíduos com dor crônica não específica no pescoço em comparação aos controles. ${ }^{29}$

O comportamento dos músculos cervicais em indivíduos com diferentes cefaleias, durante atividades de força máxima e submáxima, também já foi verificado em alguns estudos. ${ }^{30-33}$ Sabe-se que indivíduos com cefaleia do tipo tensional e mulheres com migrânea crônica apresentam uma redução significativa da força dos músculos extensores cervicais. $^{30,33}$ Por sua vez, em indivíduos com cefaleia cervicogênica, nota-se uma redução da força tanto dos músculos extensores quanto dos flexores cervicais. ${ }^{31}$

Ao avaliar-se a atividade eletromiográfica dos músculos cervicais em indivíduos com cefaleia, a literatura demonstra que indivíduos com cefaleia cervicogênica e cefaleia do tipo tensional apresentam um aumento da amplitude do sinal eletromiográfico do músculo esternocleidomastóideo durante o teste de flexão craniocervical (TFCC). ${ }^{31,32}$ Todavia, apenas em indivíduos com cefaleia cervicogênica a maior atividade elétrica do músculo esternocleidomastóideo foi significativa. ${ }^{31}$ Em indivíduos com migrânea, especificamente, observa-se um aumento na coativação dos músculos extensores cervicais durante uma tarefa máxima. ${ }^{33}$

A razão de força dos músculos cervicais foi verificada apenas em indivíduos com cefaleia do tipo tensional. Madsen et $\mathrm{al}^{30}$ calcularam a razão de força dos músculos extensores/flexores cervicais em indivíduos com cefaleia do tipo tensional e observaram uma redução dessa razão em comparação ao grupo controle. Para os autores, a menor razão de força dos músculos extensores/flexores cervicais pode ser um fator em potencial para a cronificação da doença. ${ }^{30}$

Sabe-se que a existência de um desequilíbrio muscular entre a força de extensão e flexão da coluna cervical pode apresentar um efeito negativo importante na estabilização da mesma ${ }^{34}$ demostrando a importância da clareza dessa condição em pacientes com migrânea que sabidamente já apresentam alterações na produção de força dos músculos cervicais. ${ }^{33}$

A importância de verificar-se a razão, seja ela de força, atividade muscular ou de testes, foi demonstrada para os músculos da coluna lombar. Ao realizar-se a razão dos músculos flexores/extensores lombares e extensores/flexores de quadril no âmbito de testes de resistência obteve-se resultados capazes de discriminar significativamente indivíduos com dor lombar crônica daqueles sem dor. ${ }^{35}$ Mesmo sabendo-se que a razão 
é mais informativa do que os dados isolados de força muscular e que a mesma pode ser utilizada para avaliar e tratar os pacientes de forma mais efetiva, a razão é negligenciada. ${ }^{36,37}$

Dessa forma, sabendo-se das diversas alterações musculoesqueléticas apresentadas por indivíduos com migrânea e diante da riqueza de informações que poderão ser obtidas pelo cálculo das razões de força e atividade muscular evidencia-se a importância de realizar-se esse estudo. Hipotetizamos que indivíduos com migrânea apresentarão um pior desempenho muscular, demonstrado por meio de tarefas máximas e submáximas e, consequentemente, razões de força e eletromiográfica diferentes em comparação ao grupo controle. Acreditamos que nossos resultados irão contribuir para melhorias na avaliação e tratamento de indivíduos com migrânea. 


\section{Objetivo}

Nosso objetivo foi comparar a razão extensores/flexores dos músculos cervicais em indivíduos com migrânea em relação a controles no âmbito de força muscular e atividade eletromiográfica durante a mensuração da força muscular na contração isométrica voluntária máxima (CIVM) e TFCC. Além disso, verificar o desempenho muscular dos flexores profundos, de ambos os grupos, por meio do TFCC. 


\section{Materiais e métodos}

\subsection{Cálculo Amostral}

Foi realizado um cálculo amostral utilizando-se o programa $G$ Power 3.1.9.2 baseado em dados de um estudo piloto. Os parâmetros adotados foram a média e o desvio padrão da razão do pico da força muscular dos extensores sobre o pico da força muscular dos flexores cervicais. O estudo piloto foi composto de 10 mulheres, 5 mulheres com migrânea e 5 controles, com média de 2,37 ( $\mathrm{DP}=0,47)$ e 2,60 ( $\mathrm{DP}=0,34)$, respectivamente, gerando um effect size de 0,55. Foi adotado um nível de significância de 0,05 e um poder de $80 \%$. O tamanho amostral mínimo necessário foi de 52 participantes em cada grupo.

\subsection{Participantes}

Das 102 pacientes com potencial elegibilidade que passaram pelo Ambulatório de Cefaleia e Algias Craniofaciais do Hospital das Clínicas da Faculdade de Medicina de Ribeirão Preto da Universidade de São Paulo (ACEF - HCFMRP/USP), foram incluídas no grupo migrânea 52 voluntárias do sexo feminino com idade entre 18 e 55 anos e diagnóstico de migrânea de acordo com a Classificação Internacional de Cefaleias (CICIII). ${ }^{7}$ Foram excluídas da amostra aquelas participantes que apresentaram diagnóstico de outras cefaleias, associadas ou não à migrânea, abuso de analgésico, histórico de trauma na região da cervical ou da face, gravidez, diagnóstico de hérnia ou degeneração discal na cervical, doenças sistêmicas ou bloqueio anestésico nos últimos 3 meses. Além disso, foram excluídas aquelas que apresentaram três ou menos dias de dor por mês (Figura 1). Para o grupo controle, das 70 possíveis voluntárias, foram avaliadas 52 mulheres com idade entre 18 e 55 anos e sem histórico de migrânea ou outro tipo de cefaleia e sem relato de cervicalgia. Os critérios de exclusão para este grupo seguiram os do grupo migrânea (Figura 2). 


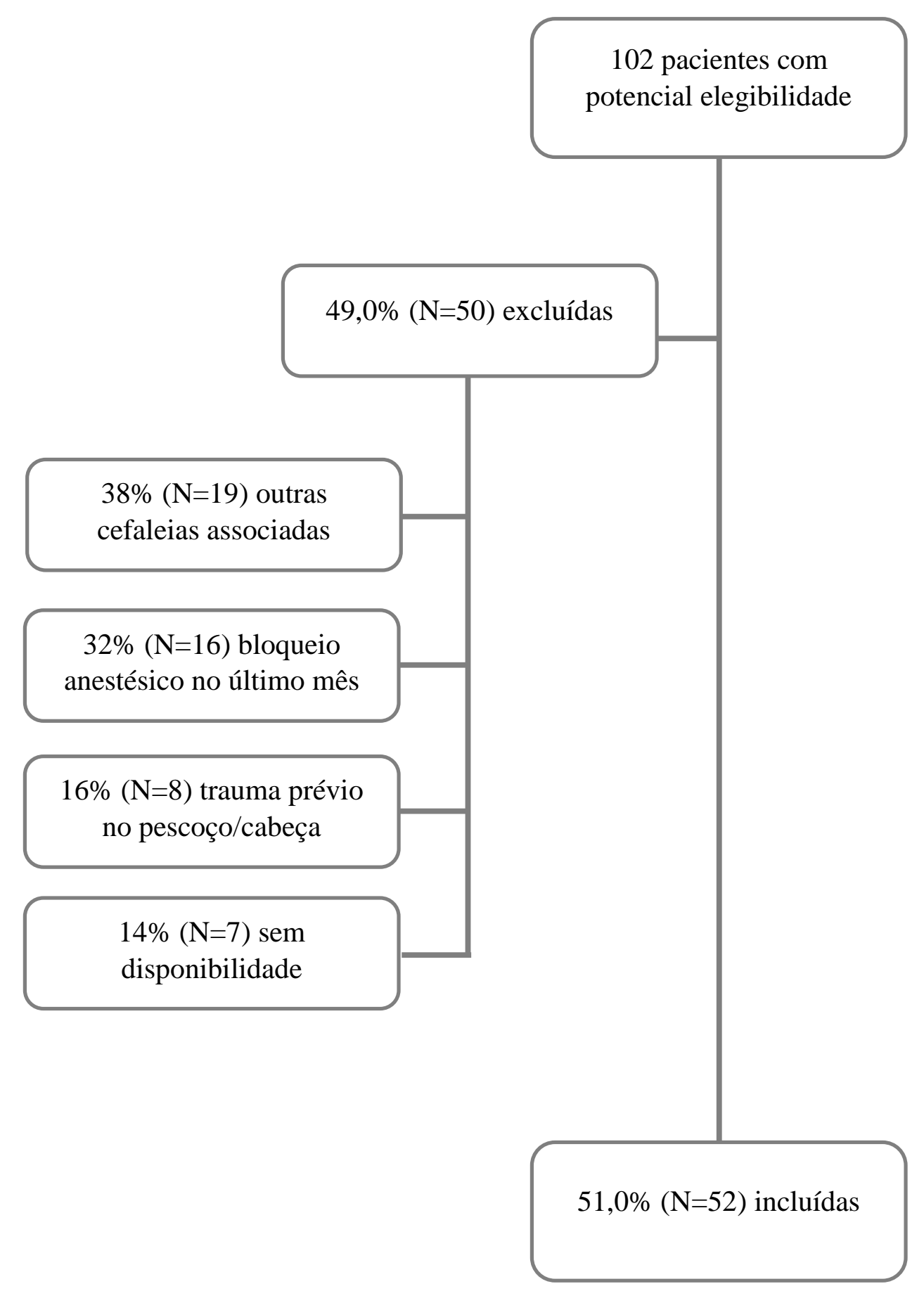

Figura 1. Fluxograma de pacientes do grupo migrânea. 


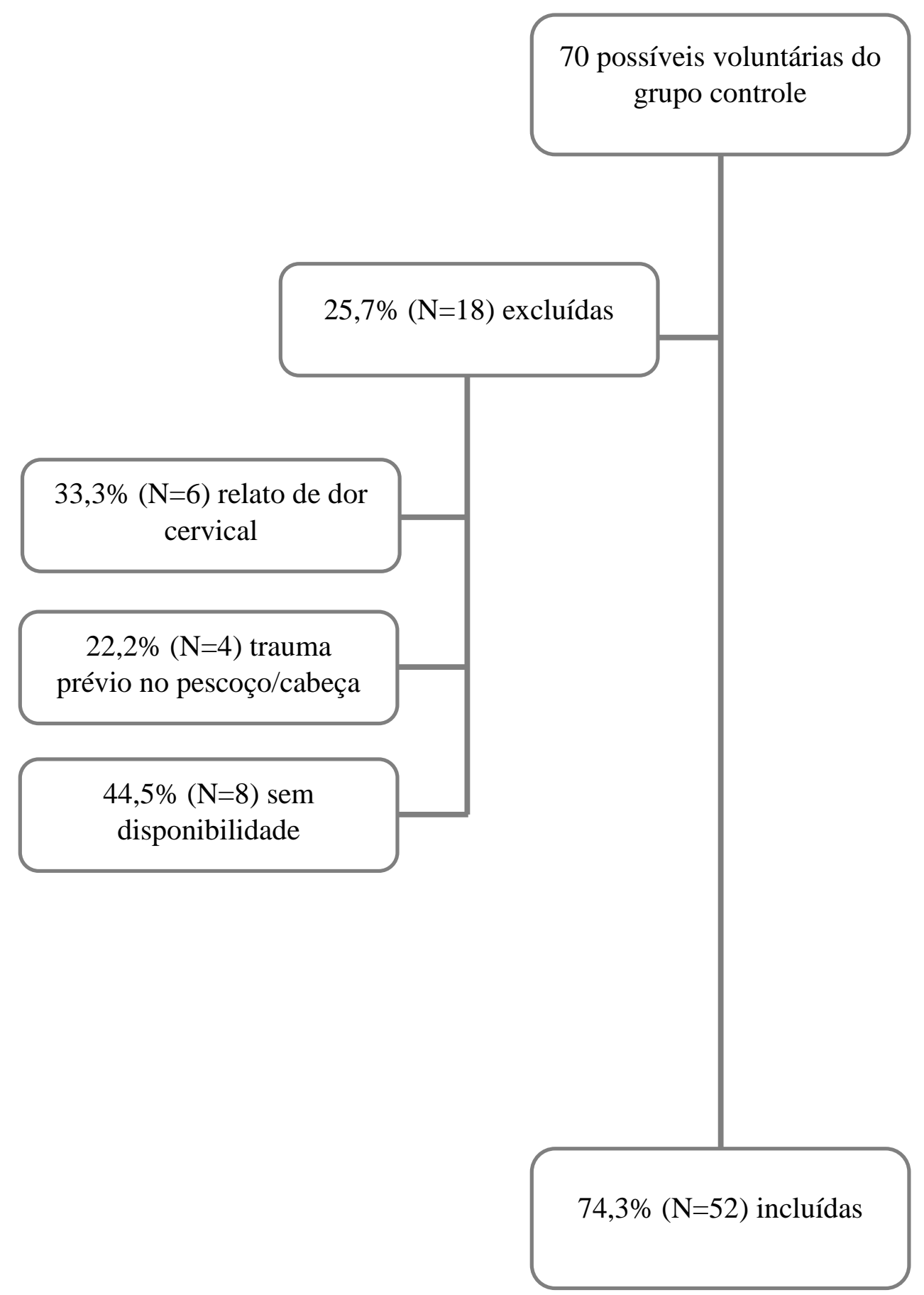

Figura 2. Fluxograma de voluntárias do grupo controle. 


\subsection{Procedimentos}

Após a consulta com um neurologista experiente e confirmação do diagnóstico de migrânea, as participantes foram triadas por um fisioterapeuta treinado, de acordo com os critérios de inclusão e exclusão. Nessa fase, foram registrados dados como idade, peso, altura, escolaridade e características da migrânea (Apêndice 1). Em seguida, aquelas que aceitaram participar do estudo passaram por uma avaliação fisioterapêutica, na qual foram aplicados três questionários: Neck Disability Index, Migraine Disability Assessment e 12item Allodynia Symptom Checklist. Além disso, foram realizados testes de força e desempenho muscular da região cervical, sendo o último por meio do TFCC, ambos com registro eletromiográfico. A amostra que constituiu o grupo controle foi triada na população, na própria universidade ou ainda, mulheres acompanhantes no ACEF HCFMRP/USP que preenchiam os critérios de inclusão. Para esse grupo, dados como idade, peso, altura e escolaridade também foram coletados, e assim como no grupo migrânea, o grupo controle passou pelos testes de mensuração da força muscular e realizou o TFCC, ambos com registro eletromiográfico.

\subsubsection{Questionários}

- Neck Disability Index:

Consiste de 10 questões relacionadas a tarefas diárias, como por exemplo, cuidados pessoais, sono e leitura. ${ }^{38}$ A pontuação varia de 0 a 50 pontos, classificando o indivíduo em: sem incapacidade (0-4 pontos), incapacidade leve (5-14 pontos), incapacidade moderada (15-24 pontos), incapacidade severa (25-35 pontos) e incapacidade total (36 ou mais pontos). ${ }^{38,39}$ É um instrumento válido e com bom poder de resposta, ${ }^{40}$ sendo o instrumento de avaliação mais recomendado para avaliar a incapacidade funcional associada à dor cervical ${ }^{41}$ (Anexo 1).

- Migraine Disability Assessment:

Questionário autoaplicável que conta com cinco questões sobre a limitação na participação em atividades no trabalho, na escola e no ambiente domiciliar devido à migrânea. ${ }^{42}$ Sua confiabilidade e validade foram comprovadas por meio de métodos padrões em diversos países. ${ }^{43,44}$ Os indivíduos podem ser classificados em: sem incapacidade ou incapacidade leve (0-5 pontos), incapacidade suave (6-10 pontos), 
incapacidade moderada (11-20 pontos) e incapacidade severa (21 ou mais pontos) ${ }^{42}$ (Anexo 2).

\section{- 12-item Allodynia Symptom Checklist:}

Classifica o indivíduo quanto à severidade da alodinia cutânea, ${ }^{45}$ sua pontuação varia entre 0 e 24 pontos e permite classificar o sujeito em: sem alodinia ( 0 -2 pontos), alodinia leve (3-5 pontos), alodinia moderada (6-8 pontos) e alodinia severa (9 ou mais pontos). ${ }^{46}$ A versão brasileira foi traduzida e validada por Florencio et $\mathrm{al}^{45}$ que demonstrou tratar-se de um instrumento rápido, prático e confiável para a avaliação da alodinia cutânea na prática clínica ${ }^{45}$ (Anexo 3 ).

\subsubsection{Exame físico}

\section{- Eletromiografia:}

Para verificarmos a ativação dos músculos cervicais superficiais durante a mensuração da força na CIVM e TFCC a eletromiografia foi utilizada. Os dados eletromiográficos foram analisados durante ambos os testes e a razão entre os músculos extensores/flexores cervicais foi calculada. O posicionamento do paciente e os comandos verbais utilizados estão descritos abaixo nos subitens "Mensuração da força muscular na contração isométrica voluntária máxima" e "Teste de flexão craniocervical". Para a coleta de dados eletromiográficos, sensores de superfície sem fio (Trigno ${ }^{T M}$ Wireless System, Delsys Inc. Boston, MA) foram firmemente fixados, bilateralmente, por fitas adesivas dupla-face ${ }^{33}$ sobre os músculos:

$\checkmark$ Porção distal do ventre muscular do esternocleidomastóideo ${ }^{47}$

$\checkmark$ Ventre muscular do músculo esplênio da cabeça, localizado a nível de C2-C3 entre o esternocleidomastóideo e o trapézio superior ${ }^{48}$

$\checkmark$ Ventre muscular do escaleno anterior, paralelo a porção clavicular do músculo esternocleidomastóideo $^{47}$

$\checkmark$ Ponto médio do trapézio superior. ${ }^{49}$

Cada um dos oito sensores utilizados continha quatro barras paralelas de 99,9\% de Ag com uma área de contato de $50 \mathrm{~mm}^{2}(5 \times 1 \mathrm{~mm}$ e distância intereletrodo de 10 $\mathrm{mm}$ ), sendo dois eletrodos ativos e dois estabilizadores, sistema este que dispensa o eletrodo de referência. Os sinais eletromiográficos foram adquiridos pelo programa $E M G$ Works $^{\circledR}$ versão 4.1 .5 (Delsys Inc.), sendo os mesmos ampliados $($ ganho $=300) \mathrm{e}$ 
amostrados a $4000 \mathrm{~Hz}$ por canal. Para ambos os testes, os sinais eletromiográficos brutos foram processados por uma rotina customizada do $M A T L A B^{\circledR}$ responsável por filtrá-los a uma faixa de frequência de $20-500 \mathrm{~Hz}$, utilizando-se de um filtro de $4^{\text {a }}$ ordem (Butterworth). Previamente a colocação dos sensores, a pele recebeu limpeza adequada com a utilização de álcool e os pelos foram removidos para a redução da impedância.

- Mensuração da força muscular na contração isométrica voluntária máxima:

A mensuração da força na CIVM dos músculos flexores e extensores cervicais foi realizada de acordo com o protocolo de Florencio et $\mathrm{al}^{33}$ o qual apresentou reprodutibilidade excelente para flexores $(0,78)$ e extensores $(0,81)$ cervicais. Assim como no protocolo original, a mensuração da força na CIVM foi realizada por um fisioterapeuta treinado, utilizando-se um dinamômetro isométrico manual (Lafayette Instrument Company®, modelo 2201163, Lafayette, IN, USA) que permaneceu fixado a um cinto não elástico, evitando-se possíveis interferências de forças externas.

Antes do início da coleta foi realizada uma familiarização com a tarefa e foi solicitada uma contração submáxima de flexão e extensão. Em seguida, a CIVM foi solicitada e foram coletadas três repetições de três segundos cada para ambos os grupos musculares. Foi permitido um intervalo de 20 segundos entre cada repetição e de três minutos entre cada movimento.

Os posicionamentos adotados durante o teste foram:

$\checkmark \quad$ Força de Flexão: paciente em decúbito dorsal com joelhos e quadris estendidos. Cintos Velcro ${ }^{\circledR}$ (VELCRO B.V., Manchester, NH, USA) foram colocados firmemente, um cruzando a pelve, e outro o tronco, afim de reduzir movimentos e compensações musculares durante a tarefa. O dinamômetro isométrico manual foi posicionado em uma linha média imaginária sobre o osso frontal (Figura 3).

$\checkmark$ Força de Extensão: paciente em decúbito ventral também com cintos Velcro ${ }^{\circledR}$ (VELCRO B.V., Manchester, NH, USA) colocados firmemente cruzando-se a pelve e o tronco. Por sua vez, o dinamômetro isométrico manual foi posicionado em uma linha média imaginária sobre o osso occipital (Figura 4).

O pico de força foi registrado em quilograma-força (kgf), e posteriormente convertido para newton $(\mathrm{N})$ e normalizado pelo peso corporal do indivíduo. A fórmula 
utilizada para essa conversão foi: valor obtido pelo dinamômetro isométrico manual (kgf) * 9.81 / peso corporal $(\mathrm{kg})$.

Após a conversão dos resultados para $\mathrm{N}$ e normalização pelo peso corporal, foi realizada a média das três repetições para cada indivíduo, tanto para o movimento de flexão quanto de extensão. Com base nessas médias normalizadas, foi então feita a razão dos músculos extensores/flexores cervicais para cada indivíduo e em seguida, os resultados foram analisados estatisticamente.

O registro do sinal eletromiográfico dos músculos flexores e extensores cervicais ocorreu durante a mensuração da força muscular na CIVM, para ambos os movimentos. A aquisição dos dados eletromiográficos foi iniciada e em seguida, foi solicitada a CIVM, a qual a participante manteve por três segundos, sendo encorajada pelo terapeuta por meio dos comandos verbais de "força, força, mais força". Para o processamento, o RMS foi calculado com base em uma janela de dois segundos para cada repetição da CIVM, sendo selecionados individualmente e manualmente os dois segundos com melhor qualidade do sinal eletromiográfico. Para a análise individual dos músculos flexores e extensores cervicais, incialmente realizou-se a normalização dos dados eletromiográficos, onde o RMS médio de cada músculo foi dividido pelo RMS pico daquele próprio músculo durante sua tarefa agonista e em seguida, foi calculada a média entre as repetições e entre os lados, direito e esquerdo. Ainda, afim de melhor visualizar a magnitude da ativação muscular em ambos os grupos, os dados eletromiográficos brutos foram listados (Apêndice 2). Para a razão eletromiográfica, a média para as repetições e lados de cada músculo foi calculada. Em seguida, foi feita a soma do RMS dos flexores, esternocleidomastóideo e escaleno anterior e extensores, trapézio superior e esplênio da cabeça. E por fim, a soma dos músculos extensores foi dividida pela soma dos flexores. 


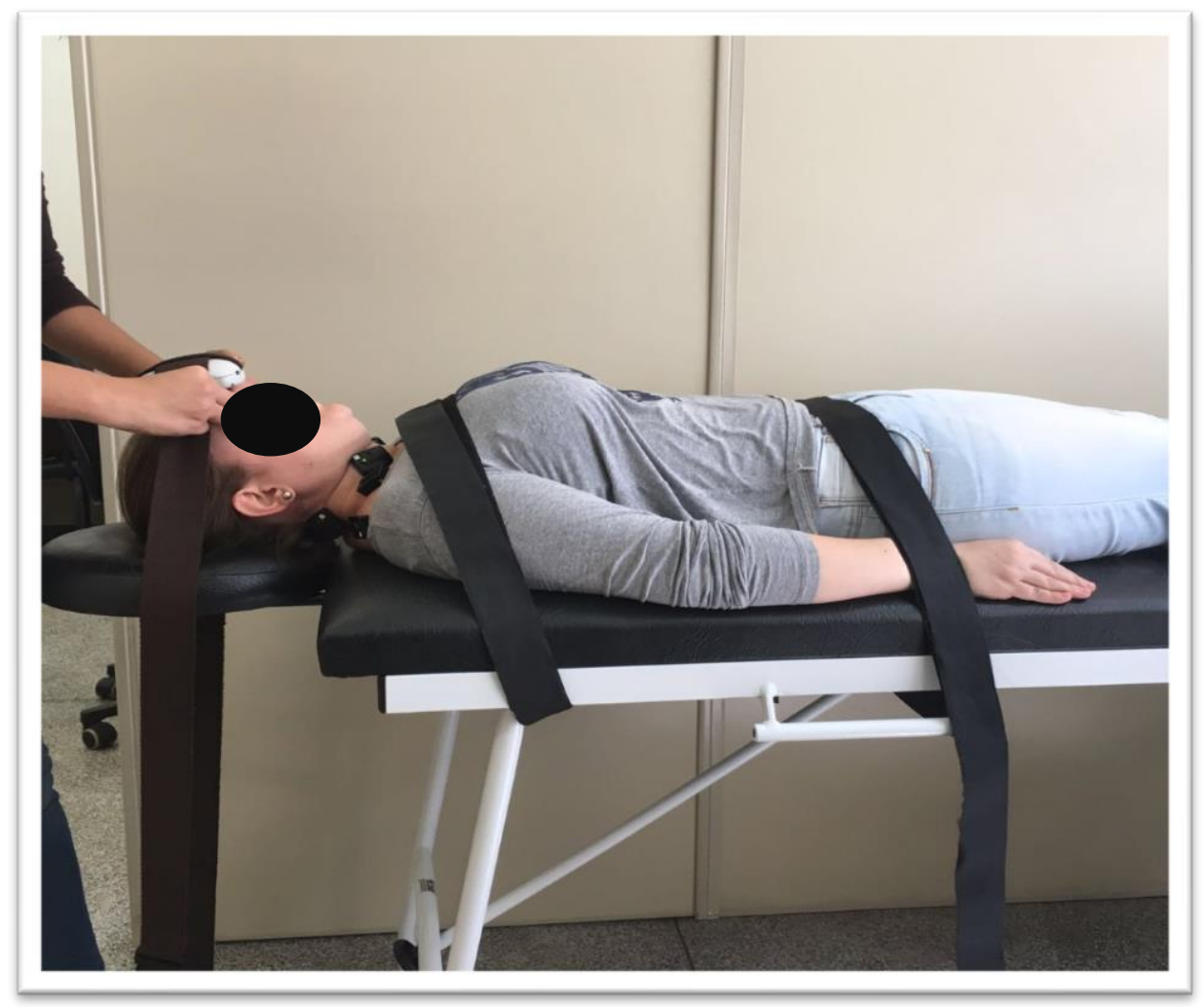

Figura 3. Posicionamento da paciente durante a mensuração da força dos músculos flexores cervicais.

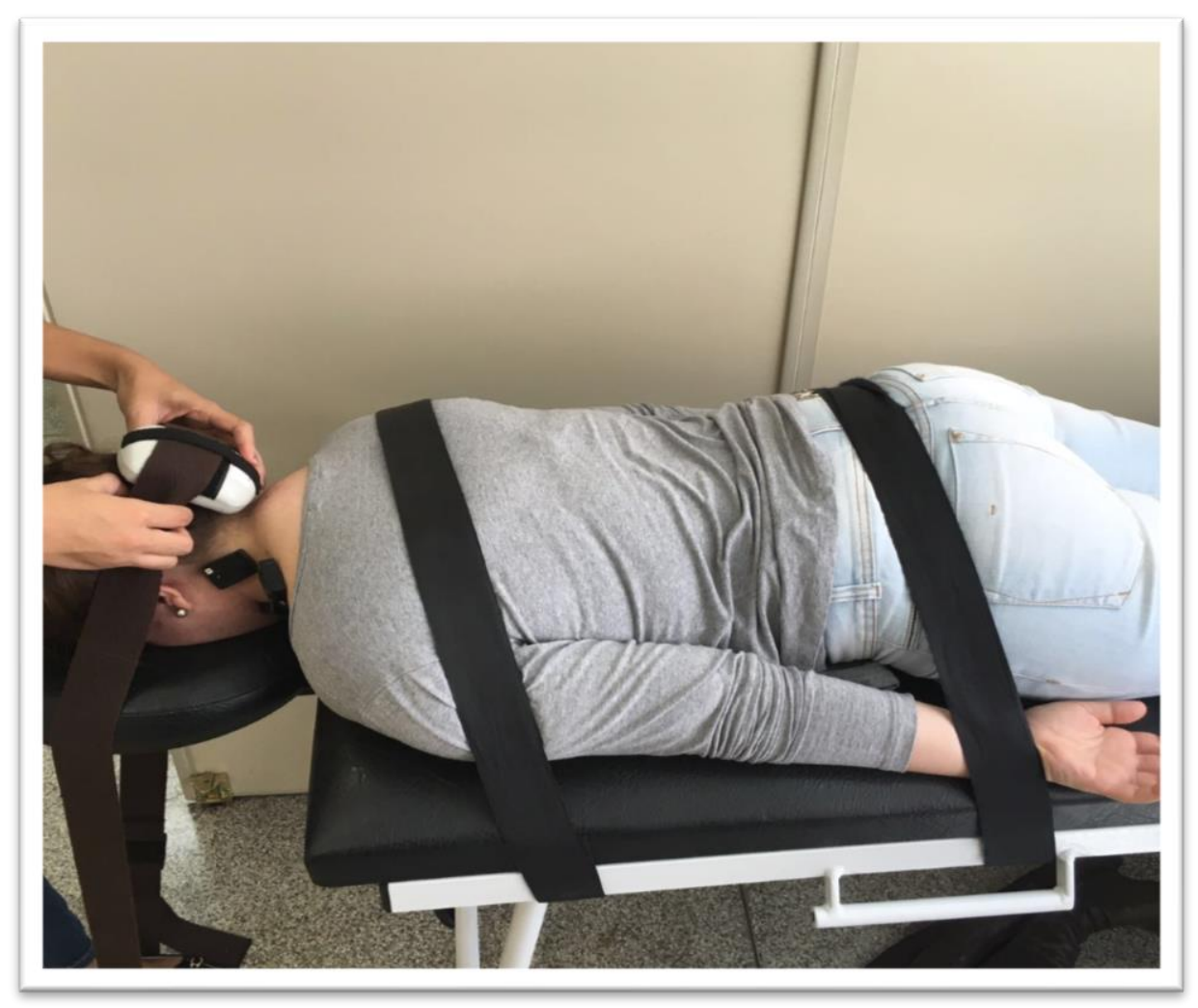

Figura 4. Posicionamento da paciente durante a mensuração da força dos músculos extensores cervicais. 


\section{- $\quad$ Teste de flexão craniocervical:}

O desempenho muscular dos flexores profundos da cervical foi avaliado por meio do TFCC, sendo o mesmo um teste de controle neuromotor que nos permite avaliar a ativação e a resistência isométrica desses músculos. ${ }^{50} \mathrm{O}$ teste foi realizado com a participante em decúbito dorsal, a qual permaneceu com os membros inferiores relaxados e o pescoço na posição neutra. ${ }^{50} \mathrm{O}$ dispositivo de pressão Stabilizer Pressure Biofeedback® (Chatanooga, Hixson, TN, USA) foi posicionado na região posterior do pescoço da participante e inicialmente, inflado a $20 \mathrm{mmHg}$. A tarefa da participante era aumentar $2 \mathrm{mmHg}$ a cada estágio, totalizando cinco estágios (30 $\mathrm{mmHg}$ ), e manter a pressão por 10 segundos sem realizar compensações, sendo essas: retração ou elevação da cabeça e uso excessivo dos flexores superficiais. ${ }^{50}$ Para nos assegurarmos de que a participante estava enxergando a marcação para a qual deveria manter a pressão foi desenvolvido um suporte, no qual o dispositivo de pressão ficava ajustado de acordo com a altura de cada voluntária (Figura 5).

A princípio, foi realizada a familiarização e caso a participante realizasse algum tipo de compensação, era desencorajada. Em seguida, iniciou-se o teste, no qual foi realizada uma repetição para cada estágio e a voluntária foi orientada a realizar um movimento de flexão de cabeça, semelhante ao movimento de "assentir" e mantê-lo por 10 segundos, conforme dito anteriormente. Um período de descanso de 30 segundos entre um estágio e outro foi permitido. Todas as voluntárias realizaram os cinco estágios do teste para que os dados eletromiográficos fossem coletados. Entretanto, para verificarmos o desempenho dos músculos flexores profundos no TFCC, o último estágio em que não houve compensação foi anotado e tabulado como resultado para o teste. Posteriormente, foi verificada a percentagem e distribuição das voluntárias nos cinco estágios do teste.

A aquisição do sinal eletromiográfico dos músculos selecionados iniciou-se no momento que a voluntária atingiu o estágio solicitado e teve duração de 10 segundos. $\mathrm{O}$ último estágio em que a voluntária não realizou compensações foi anotado. Para o processamento dos sinais eletromiográficos dos estágios do TFCC, o RMS foi calculado a partir de uma janela central de cinco segundos. Utilizando-se desses valores, a média entre os lados foi calculada e em seguida, foi feita a soma do RMS dos flexores, esternocleidomastóideo e escaleno anterior e extensores, trapézio superior e esplênio da 
cabeça. Assim como na mensuração da força muscular, a razão foi calculada por meio da divisão da soma dos extensores pela soma dos flexores.

Além da razão eletromiográfica durante os cinco estágios do TFCC, verificou-se os valores médios de sinal eletromiográfico de cada músculo durante o teste. Para isso, o RMS médio de cada músculo foi normalizado pelo RMS médio obtido durante a CIVM de flexão ou extensão, de acordo com a função muscular. Após a normalização dos dados, realizou-se a média entre os lados e a comparação entre os grupos foi realizada.

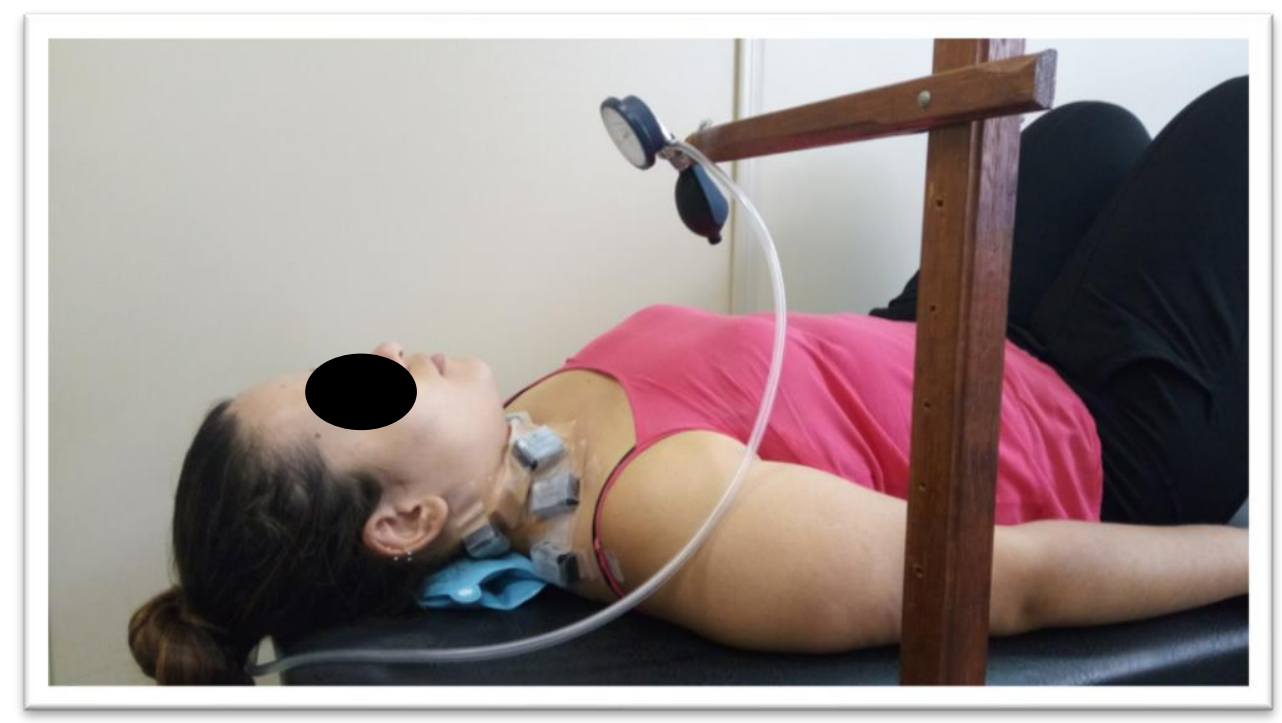

Figura 5. Posicionamento da paciente durante o TFCC e dispositivo de suporte para a visualização da pressão. 


\subsection{Aspectos éticos}

O estudo foi aprovado pelo Comitê de Ética em Pesquisa da Faculdade de Medicina de Ribeirão Preto da Universidade de São Paulo (FMRP/USP) com $\mathrm{n}^{\circ}$ 6861/2016 (Anexo 4). Após aprovação do mesmo, as coletas foram iniciadas e as participantes assinaram o Termo de Consentimento Livre e Esclarecido (TCLE) com informações e esclarecimento de possíveis dúvidas em relação à pesquisa (Anexo 5).

\subsection{Análises estatísticas}

Foi realizada uma análise descritiva de todas as variáveis, sendo os dados apresentados na forma de média, desvio padrão e frequência de observações. Para a comparação entre os grupos, inicialmente verificou-se a normalidade dos dados por meio do teste de Shapiro-Wilk e gráficos de dispersão. Foi utilizado o teste U Mann Whitney para se comparar a idade entre os grupos. Diante da diferença, o teste ANCOVA foi realizado utilizando-se a idade como covariável para comparar os grupos, migrânea e controle, quanto as variáveis de força muscular, dados eletromiográficos e razão, tanto de força muscular quanto eletromiográfica. Para a análise da distribuição dos grupos nos cinco estágios no TFCC foi realizado um teste qui quadrado $\left(X^{2}\right)$ e em seguida foi realizado um post hoc de proporção. Os cálculos foram realizados por meio do software SPSS versão 20.0 e um nível de significância de 0,05 foi adotado. 


\section{Resultados}

Foram incluídas no estudo 52 mulheres no grupo migrânea e 52 no grupo controle. A média de idade, em anos, no grupo migrânea foi de 33,8 (DP=10,6) e para o grupo controle 28,9 $(\mathrm{DP}=8,3)(p=0,02)$. As características da migrânea encontram-se descritas na Tabela 1. Observou-se que 86,3\% das pacientes com migrânea apresentavam algum nível de incapacidade devido à doença e 92,3\% tinham alodinia cutânea, sendo leve, moderada ou severa.

Tabela 1. Descrição das características da migrânea.

\section{Grupo migrânea $(\mathrm{N}=52)$}

\section{Características}

Média (DP)

Tempo de doença (anos)

$17,4(10,7)$

Frequência (dias/mês)

Intensidade (END)

Relato de cervicalgia ( $[\%])$

$\operatorname{Sim}$

$43(82,7 \%)$

Não

$9(17,3 \%)$

Questionários (n[\%])

NDI

Sem incapacidade

$11(21,2 \%)$

Incapacidade leve

$23(44,2 \%)$

Incapacidade modera

$15(28,8 \%)$

Incapacidade severa

$3(5,8 \%)$

MIDAS

Sem incapacidade

$7(13,7 \%)$

Incapacidade leve

$5(9,9 \%)$

Incapacidade modera

$11(21,5 \%)$

Incapacidade severa

$28(54,9 \%)$

ASC-12/Brasil

Sem alodinia cutânea

$4(7,7 \%)$

Alodinia cutânea leve

$10(19,2 \%)$

Alodinia cutânea moderada

$9(17,3 \%)$

Alodinia cutânea severa

$29(55,8 \%)$ 
END: escala numérica de dor; NDI: Neck Disability Index; MIDAS: Migraine Disability Assessment; ASC-12/Brasil: 12-item Allodynia Symptom Checklist/Brazil.

- Mensuração da força muscular na contração isométrica voluntária máxima

1. Dados clínicos:

A comparação entre os grupos em relação a mensuração da força muscular demonstrou que o grupo migrânea apresenta uma diminuição da força dos músculos flexores cervicais $(\mathrm{F}=11,47 ; p=0,00)$ e consequentemente, uma maior razão da força entre os músculos extensores e flexores $(\mathrm{F}=4,16 ; p=0,04)$ em comparação ao grupo controle (Tabela 2).

Tabela 2. Dados da força dos músculos cervicais no grupo migrânea e controle e a razão da força dos músculos extensores/flexores.

\begin{tabular}{|c|c|c|c|c|c|}
\hline & & $\begin{array}{c}\text { Grupo } \\
\text { migrânea } \\
(\mathbf{N}=52)\end{array}$ & $\begin{array}{c}\text { Grupo } \\
\text { controle } \\
(\mathrm{N}=52)\end{array}$ & & \\
\hline & & Média (DP) & Média (DP) & Valor F & Valor $p$ \\
\hline $\begin{array}{l}\text { Flexores } \\
\text { cervicais }\end{array}$ & $\begin{array}{l}\text { Força }_{n}(\mathrm{~N} / \mathrm{kg}) \\
\text { Força }(\mathrm{N})\end{array}$ & $\begin{array}{l}0,55(0,22) \\
35,3(14,0)\end{array}$ & $\begin{array}{l}0,73(0,29) \\
48,4(21,2)\end{array}$ & $\begin{array}{c}11,47 \\
\text { NA }\end{array}$ & $\begin{array}{l}0,00 \\
\text { NA }\end{array}$ \\
\hline $\begin{array}{l}\text { Extensores } \\
\text { cervicais }\end{array}$ & $\begin{array}{l}\text { Força }_{n}(\mathrm{~N} / \mathrm{kg}) \\
\text { Força }(\mathrm{N})\end{array}$ & $\begin{array}{l}1,34(0,53) \\
85,7(31,7)\end{array}$ & $\begin{array}{l}1,40(0,45) \\
91,9(32,2)\end{array}$ & $\begin{array}{l}0,37 \\
\text { NA }\end{array}$ & $\begin{array}{l}0,54 \\
\mathrm{NA}\end{array}$ \\
\hline $\mathrm{EX} / \mathrm{FL}$ & $\begin{array}{c}\text { Razão } \\
\text { Razão Log }\end{array}$ & $\begin{array}{l}2,5(1,0) \\
0,4(0,2)\end{array}$ & $\begin{array}{l}2,2(1,1) \\
0,3(0,2)\end{array}$ & $\begin{array}{l}\text { NA } \\
4,16\end{array}$ & $\begin{array}{l}\text { NA } \\
0,04\end{array}$ \\
\hline $\begin{array}{l}\text { Força }{ }_{n}=\text { força } \\
\text { força dos mús }\end{array}$ & $\begin{array}{l}\text { ormalizada pelo } \mathrm{p} \\
\text { los extensores pe }\end{array}$ & $\begin{array}{l}\text { o corporal do i } \\
\text { s músculos fles }\end{array}$ & $\begin{array}{l}\text { ivíduo; } \mathrm{NA}=\text { nã } \\
\text { es; }{ }_{\text {Log }}=\text { valores }\end{array}$ & $\begin{array}{l}\text { aplica; EX } \\
\text { base em }\end{array}$ & $\begin{array}{l}\text { razão de } \\
\text { prmação }\end{array}$ \\
\hline
\end{tabular}




\section{Dados eletromiográficos:}

Foram avaliados os dados eletromiográficos dos músculos flexores e extensores cervicais durante a CIVM e não se observou diferença estatística entre os grupos na amplitude do RMS normalizado durante as tarefas para ambos os músculos (Tabela 3).

Tabela 3. Amplitude do RMS normalizado dos músculos flexores e extensores cervicais durante a CIVM.

\begin{tabular}{|c|c|c|c|c|}
\hline & $\begin{array}{c}\text { Grupo } \\
\text { migrânea } \\
(\mathbf{N}=52)\end{array}$ & $\begin{array}{c}\text { Grupo } \\
\text { controle } \\
(\mathrm{N}=52)\end{array}$ & & \\
\hline & Média (DP) & Média (DP) & Valor F & Valor $p$ \\
\hline $\mathrm{ECOM}_{\mathrm{Log}}$ & $-0,07$ & $-0,08$ & 0,27 & 0,60 \\
\hline
\end{tabular}

Flexores

EA $_{\log } \quad-0,10 \quad-0,09 \quad 0,04 \quad 0,84$

$\begin{array}{lllll}\text { EC }_{\text {Log }} & -0,09 & -0,09 & 0,96 & 0,32\end{array}$

Extensores

$\begin{array}{llll}\text { TS } & 0,82 & 0,82 & 1,51\end{array}$

ECOM=esternocleidomastóideo; EA=escaleno anterior; EC=esplênio da cabeça; TS=trapézio superior; Log=valores com base em transformação logarítmica dos dados.

Ao avaliarmos a razão eletromiográfica dos músculos extensores/flexores durante a mensuração da força muscular para extensão não foram observadas diferenças estatísticas entre os grupos, sendo o valor médio de 3,0 $(\mathrm{DP}=2,5)$ para o grupo controle e $2,8(\mathrm{DP}=1,0)$ para o grupo migrânea $(\mathrm{F}=0,32 ; p=0,57)$. Entretanto, na razão eletromiográfica extensores/flexores durante a mensuração da força muscular para flexão, pudemos observar um aumento da mesma no grupo controle $(\mathrm{F}=6,45 ; p=0,01)$, o qual apresentou um valor médio de $0,4(\mathrm{DP}=0,2)$, enquanto que para o grupo migrânea o valor foi de $0,3(\mathrm{DP}=0,2)$ (Tabela 4$)$. 
Tabela 4. Razão eletromiográfica dos músculos extensores/flexores na CIVM.

\begin{tabular}{|c|c|c|c|c|}
\hline & $\begin{array}{l}\text { Grupo migrânea } \\
\qquad(\mathrm{N}=\mathbf{5 2})\end{array}$ & $\begin{array}{l}\text { Grupo controle } \\
\qquad(\mathrm{N}=52)\end{array}$ & & \\
\hline & Média (DP) & Média (DP) & Valor F & Valor $p(\mathrm{~F})$ \\
\hline $\begin{array}{l}\text { CIVM em } \\
\text { flexão }\end{array}$ & $0,3(0,2)$ & $0,4(0,2)$ & 6,45 & 0,01 \\
\hline $\begin{array}{l}\text { CIVM em } \\
\text { extensão }\end{array}$ & $2,8(1,0)$ & $3,0(2,5)$ & 0,32 & 0,57 \\
\hline
\end{tabular}

$\overline{\mathrm{CIVM}=\text { =contração isométrica voluntária máxima. }}$ 


\section{- Teste de flexão craniocervical}

\section{Dados clínicos:}

Ao verificar-se a distribuição dos grupos nos estágios do TFCC observou-se que o grupo controle apresenta um melhor desempenho muscular em relação ao grupo migrânea $(p<0,00)$ (Figura 6). O teste post hoc de proporções demonstrou que a diferença entre os grupos se encontra na pressão de $30 \mathrm{mmHg}$, ou quinto estágio $(p<0,00)$.

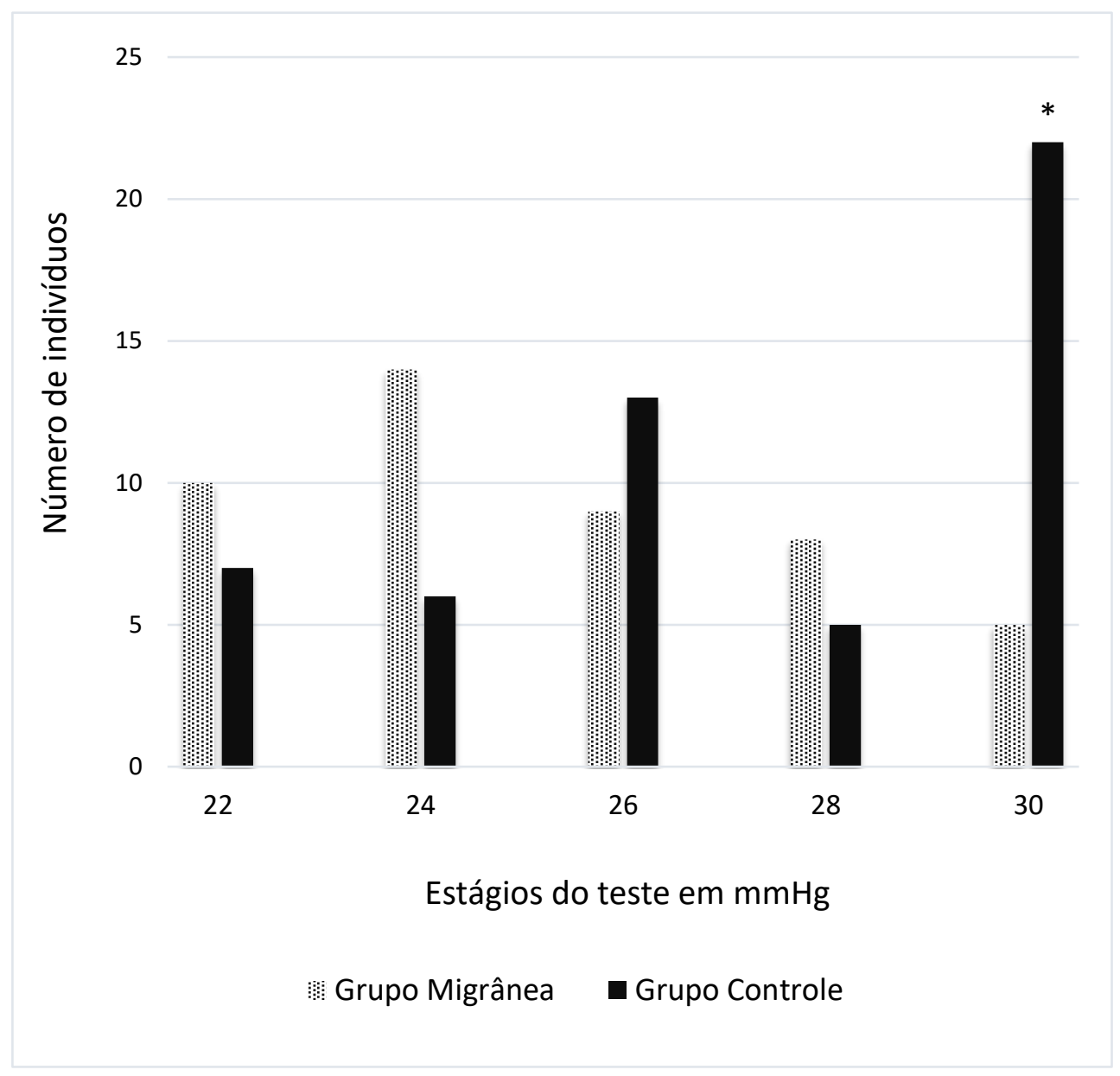

Figura 6. Distribuição dos grupos migrânea e controle durante o TFCC.

2. Dados eletromiográficos:

Não há diferença na amplitude do RMS normalizado entre os grupos, migrânea e controle, quanto aos grupos musculares, flexor e extensor, durante os cinco estágios do TFCC (Figuras 7 e 8). 


\section{Esternocleidomastóideo}
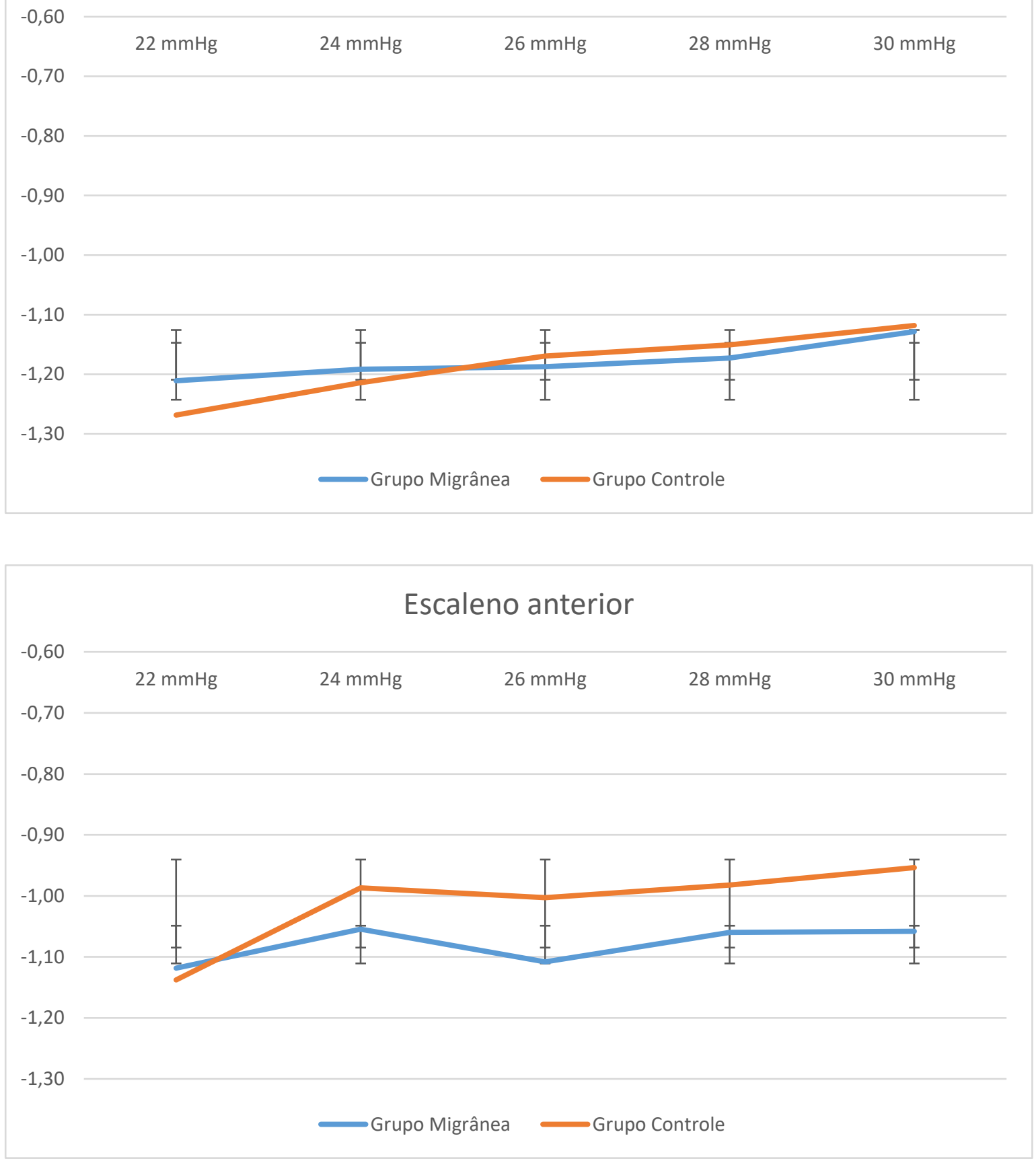

Figura 7. Distribuição dos valores médios do RMS normalizado e logaritmizado durante os cinco estágios do TFCC para os músculos flexores nos grupos migrânea e controle. 

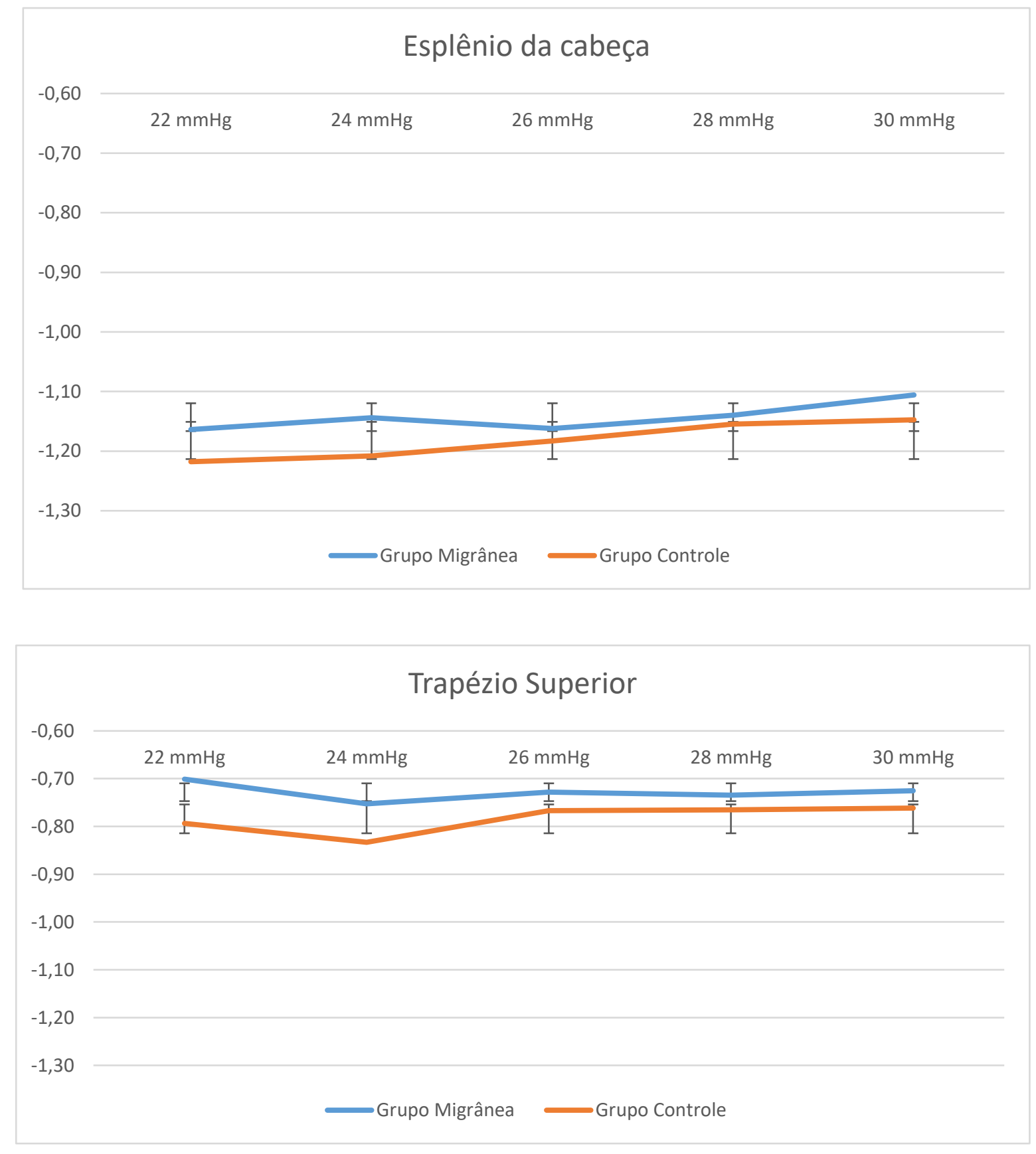

Figura 8. Distribuição dos valores médios do RMS normalizado e logaritmizado durante os cinco estágios do TFCC para os músculos extensores em ambos os grupos, migrânea e controle. 
Comparou-se a razão eletromiográfica no TFCC entre os grupos e observou-se que apenas na pressão de $30 \mathrm{mmHg}$ o grupo controle apresenta uma menor razão em relação ao grupo migrânea $(\mathrm{F}=4,05 ; p=0,047)$ (Tabela 5).

Tabela 5. Razão eletromiográfica dos músculos extensores/flexores cervicais nos cinco estágios do TFCC nos grupos migrânea e controle.

\section{Grupo migrânea Grupo controle} $(\mathrm{N}=52) \quad(\mathrm{N}=52)$

\begin{tabular}{ccccc}
\hline Pressão & Média ${ }_{\text {Log }}(\mathrm{DP})$ & Média ${ }_{\text {Log }}(\mathrm{DP})$ & Valor F & Valor $p(\mathrm{~F})$ \\
\hline $22 \mathrm{mmHg}$ & $-0,35(0,23)$ & $-0,40(0,26)$ & 0,78 & 0,37 \\
$24 \mathrm{mmHg}$ & $-0,37(0,23)$ & $-0,45(0,30)$ & 1,74 & 0,19 \\
$26 \mathrm{mmHg}$ & $-0,47(0,24)$ & $-0,37(0,33)$ & 2,42 & 0,12 \\
$28 \mathrm{mmHg}$ & $-0,40(0,27)$ & $-0,49(0,32)$ & 1,85 & 0,17 \\
$30 \mathrm{mmHg}$ & $-0,37(0,27)$ & $-0,51(0,33)$ & 4,04 & 0,047 \\
\hline
\end{tabular}

Log=valores com base em transformação logarítmica dos dados. 


\section{Discussão}

Nossos resultados revelaram um pior desempenho dos músculos cervicais em mulheres com migrânea ao compará-las a controles saudáveis devido a reduzida força dos músculos flexores cervicais, maior razão dos músculos extensores/flexores da força durante a tarefa de CIVM, menor razão entre os músculos extensores/flexores na atividade eletromiográfica durante a mesma tarefa e pior performance no TFCC com consequente aumento da razão eletromiográfica dos músculos extensores/flexores cervicais no último estágio do teste.

Até o momento, a literatura não encontrou diferenças na força dos músculos cervicais entre indivíduos com migrânea episódica e controles, ${ }^{31,33,51}$ por outro lado, uma redução significativa da força dos músculos extensores cervicais foi observada apenas para mulheres com migrânea crônica, ou seja, aquelas com maior frequência de crises. ${ }^{33}$ Contrariando estes resultados, nossos dados revelaram uma redução significativa da força dos músculos flexores cervicais em mulheres com migrânea em comparação a controles corroborando com os dados de indivíduos com dor e alterações posturais na região cervical. $^{29,36}$

A grande novidade deste estudo encontra-se nos dados da razão extensor/flexor da força dos músculos cervicais, pois até o momento, tal variável ainda não havia sido explorada em indivíduos com migrânea. A fraqueza dos músculos flexores cervicais que observamos em indivíduos com migrânea é reforçada pelos dados da razão de força dos músculos extensores/flexores que também foi diferente entre os grupos. A razão de força é um parâmetro que permite um melhor conhecimento entre função e patologia ${ }^{37}$ e revela disfunções e desequilíbrios musculares que não seriam percebidos ao avaliar-se a força isométrica isolada. ${ }^{36}$ Ou seja, mulheres com migrânea apresentam um desequilíbrio no plano sagital da musculatura cervical quando comparadas a controles já que observamos uma maior razão da força dos músculos extensores/flexores no grupo migrânea somada a uma redução na produção de força isométrica dos músculos flexores.

A eletromiografia de superfície dos músculos cervicais em si já havia sido avaliada em indivíduos com cefaleias, ${ }^{31-33,51-53}$ porém, até o momento, a razão eletromiográfica dos músculos extensores/flexores, assim como a razão de força, ainda não havia sido verificada e de acordo com os nossos resultados, o grupo migrânea apresenta uma menor razão eletromiográfica entre os músculos extensores/flexores 
durante a contração isométrica máxima para flexão, reforçando, a presença do um desequilíbrio muscular nessa população.

Em nosso estudo, a baixa razão eletromiográfica dos músculos extensores/flexores nos permite duas possíveis interpretações, ou existe uma redução na ativação dos músculos extensores ou uma atividade aumentada por parte dos músculos flexores cervicais. Ao relacionar os dados de força muscular e eletromiografia, tenderíamos a acreditar que ambas as interpretações não seriam viáveis, uma vez que a força dos músculos extensores foi semelhante entre os grupos e a força dos músculos flexores encontra-se diminuída no grupo migrânea. O sinal eletromiográfico não está relacionado diretamente à força e essa relação pode ser utilizada apenas para descrições qualitativas e com cautela. ${ }^{54} \mathrm{E}$, ao contrário do que se acreditava, que diante de uma condição dolorosa ocorreria o aumento da atividade dos músculos antagonistas e diminuição da atividade dos agonistas, a nova teoria de adaptação à dor sugere a possibilidade de um aumento, diminuição ou redistribuição dessa atividade muscular de acordo com as diferentes tarefas. $^{55}$

Assim como em uma tarefa de contração máxima, o pior desempenho muscular no grupo migrânea também foi confirmado durante uma tarefa funcional e de baixa carga, o TFCC, o qual é caracterizado como um teste clínico capaz de avaliar a precisão do movimento exclusivo de flexão cervical superior. ${ }^{56} \mathrm{O}$ mesmo já foi utilizado em diversos estudos para verificar-se a função dos músculos flexores profundos da cervical em indivíduos com dor crônica no pescoço e observou-se que esses indivíduos apresentam uma baixa performance em comparação à controles. ${ }^{18,28,50,56} \mathrm{Chiu}$ et al, ${ }^{56}$ observaram que para indivíduos saudáveis a mediana no TFCC foi de $28 \mathrm{mmHg}$ enquanto que para o grupo de indivíduos com dor cervical crônica foi de $24 \mathrm{mmHg} .{ }^{56} \mathrm{Em}$ nossos resultados, os quais são pioneiros, a mediana para o grupo controle também foi de $28 \mathrm{mmHg}$, enquanto que para o grupo migrânea foi de apenas $22 \mathrm{mmHg}$, demonstrando que indivíduos migranosos com importante sensibilização central apresentam ainda mais alteração no controle motor da região cervical do que os próprios indivíduos com dor cervical.

As alterações musculoesqueléticas na região cervical são conhecidas em indivíduos com cefaleias, entretanto, o desempenho dos flexores profundos da cervical durante o TFCC só foi avaliado em um único estudo em indivíduos com cefaleia do tipo tensional crônica. ${ }^{57}$ Em indivíduos com migrânea, o teste nunca havia sido investigado e 
por meio de nossos resultados pudemos demonstrar que mulheres com migrânea apresentam um baixo desempenho no TFCC em comparação a controles saudáveis. Apenas $5(9,6 \%)$ voluntárias do grupo migrânea conseguiram atingir $30 \mathrm{mmHg}$ sem compensações em comparação a $22(42,3 \%)$ voluntárias do grupo controle, corroborando com Fernández-de-las-Penãs et al, ${ }^{57}$ os quais observaram que apenas 3 indivíduos do grupo de cefaleia do tipo tensional atingiram $30 \mathrm{mmHg} .{ }^{57}$ Com base nesses achados inéditos, podemos, novamente, afirmar que indivíduos com migrânea apresentam uma alteração significativa no desempenho muscular da região cervical.

São muitos os estudos que avaliaram a eletromiografia dos músculos flexores no TFCC, ${ }^{28,50,53,57}$ entretanto, apenas Florencio et al $^{53}$ verificaram o comportamento eletromiográfico dos músculos extensores nessa mesma atividade e os autores observaram uma maior ativação dos músculos extensores superficiais em indivíduos com migrânea, episódica e crônica, em comparação a controles. ${ }^{53}$ Em nosso estudo, ao compararmos a ativação dos músculos flexores e extensores cervicais entre os grupos durante o TFCC, não encontramos diferenças estatisticamente significativas. Entretanto, o que de fato nos chama a atenção, é que apesar de não observamos diferenças entre a ativação dos músculos em separado, observamos diferença na razão eletromiográfica e consequentemente no comportamento muscular, entre os grupos durante o quinto estágio do teste.

Ao analisarmos os valores de razão eletromiográfica durante o TFCC, não encontramos diferenças estatísticas, entretanto, visualmente, nota-se uma progressão nos valores de razão eletromiográfica para o grupo controle, fato esse que não ocorre no grupo migrânea, onde observa-se valores semelhantes durante todos os cinco estágios do teste. Esse comportamento pode ainda ser verificado, de forma subjetiva, pelos gráficos de atividade muscular, onde observa-se uma ativação progressiva e linear dos músculos, flexores e extensores cervicais, no grupo controle, enquanto que para o grupo migrânea o padrão observado não é o mesmo. Nota-se que para os músculos extensores no grupo migrânea, há um aumento da atividade elétrica muscular desde o primeiro estágio do teste. Ou seja, no grupo controle, o aumento progressivo da ativação dos músculos flexores cervicais conforme o aumento da pressão faz com que a razão eletromiográfica diminua ao longo do teste, já para o grupo migrânea, devido a maior ativação dos músculos extensores desde o primeiro estágio, nota-se uma estagnação nos valores de razão eletromiográfica. 
Nesse sentido, acreditamos que a maior razão eletromiográfica no grupo migrânea durante a pressão de $30 \mathrm{mmHg}$ no TFCC possa refletir uma maior ativação dos músculos extensores nesses indivíduos e reforçar a alteração no controle motor da região cervical em comparação a controles por meio da redistribuição da atividade e consequente redução da qualidade da tarefa executada. ${ }^{55}$

Como pontos fortes do nosso estudo, podemos dizer que ele é o primeiro a verificar e afirmar que indivíduos com migrânea apresentam pior desempenho dos músculos flexores profundos em comparação aos indivíduos controles, observado pelo TFCC. Além disso, nosso estudo foi o primeiro a analisar a razão eletromiográfica dos músculos extensores/flexores cervicais durante o mesmo teste. Por meio dos nossos resultados podemos afirmar que mulheres com migrânea apresentam um desequilíbrio muscular da região cervical e que a razão, seja ela de força ou eletromiográfica, deve ser uma medida a ser avaliada nos demais estudos. Apesar dos resultados pioneiros, algumas limitações devem ser consideradas. Primeiro, a nossa amostra é composta apenas por mulheres que foram recrutadas em um hospital terciário e dessa forma, não podemos generalizar nossos resultados à população. E segundo, sabe-se que o TFCC não é representativo de atividades rotineiras, entretanto, o mesmo é o mais indicado para verificar-se o desempenho dos músculos cervicais, sobretudo em indivíduos com dor cervical. $^{18,58,59}$ 


\section{Conclusão}

De acordo com os nossos resultados podemos concluir que mulheres com migrânea apresentam um notável desequilíbrio dos músculos flexores e extensores cervicais em comparação a controles não apenas na produção de força, mas também na atividade muscular. 


\section{Referências}

1. GOADSBY, P. J. et al. Pathophysiology of migraine: A disorder of sensory processing. Physiological Reviews, Washington, v. 97, n. 2, p. 553-622, 2017.

2. SMITH, T. R.; NICHOLSON, R. A.; BANKS, J. W. Migraine educations improves quality of life in a primary care setting. Headache, St. Louis, v. 50, n. 4, p. 600-612, 2010.

3. LIPTON, R. B.; BIGAL, M. E. Ten lessons on the epidemiology of migraine. Headache, St. Louis, v. 47, p. S2-S9, 2007. Supplement 1.

4. SILBERSTEIN, S. D.; LIPTON, R.B. Headache epidemiology. Emphasis on migraine. Neurologic Clinics, Philadelphia, v. 14, n. 2, p. 421-434, 1996.

5. KASSEBAUM, N. J. et al. Global, regional, and national disability-adjusted lifeyears (DALYs) for 315 diseases and injuries and healthy life expectancy (HALE), 1990-2015: a systematic analysis for the Global Burden of Disease Study 2015. Lancet, London, v. 388, n. 10053, p. 1603-1658, 2016.

6. FEIGIN, V. L. et al. Global, regional, and national burden of neurological disorders during 1990-2015: a systematic analysis for the Global Burden of Disease Study 2015. The Lancet Neurology, London, v. 16, n. 11, p. 877-897, 2017.

7. ICHD-III International Classification of Headache Disorders: Headache Classification Subcommittee of the International Headache Society, 3nd Edition. Cephalalgia, Oslo, v. 33, n. 9, p. 629-808, 2013.

8. ARMIJO-OLIVO, S. L. et al. Is maximal strength of the cervical flexor muscles reduced in patients with temporomandibular disorders? Archives of Physical Medicine and Rehabilitation, Philadelphia, v. 91, n. 8, p. 1236-1242, 2010.

9. SPECIALI, J. G.; ECKELI, A.L.; DACH, F. Tension-type headache. Expert Review of Neurotherapeutics, London, v. 8, n. 5, p. 839-853, 2008.

10. VOS, T. et al. Years lived with disability (YLDs) for 1160 sequelae of 289 diseases and injuries 1990-2010: a systematic analysis for the Global Burden of Disease Study 2010. Lancet, London, v. 380, n. 9859, p. 2163-2196, 2012.

11. LUEDTKE, K.; STARKE, W.; MAY, A. Musculoskeletal dysfunction in migraine patients. Cephalalgia, Oslo, v. 38, n. 5, p. 865-875, 2018.

12. CALHOUN, A. H.; FORD, S.; PRUITT, A. P. Presence of neck pain may delay migraine treatment. Postgraduate Medical Journal, London, v. 123, n. 2, p. 163168, 2011.

13. CALHOUN, A. H. et al. The prevalence of neck pain in migraine. Headache, St. Louis, v. 50, n. 8, p. 1273-1277, 2010. 
14. DODICK, D.; SILBERSTEIN, S. Central sensitization theory of migraine: Clinical implications. Headache, St. Louis, v. 46, p. S182-S191, 2006. Supplement 4.

15. BARTSCH, T.; GOADSBY, P. J. The trigeminocervical complex and migraine: Current concepts and synthesis. Current Pain Headache Reports, Philadelphia, v. 7 , n. 5, p. 371-376, 2003.

16. BARTSCH, T. Migraine and the neck: New insights from basic data. Current Pain Headache Reports, Philadelphia, v. 9, n. 3, p. 191-196, 2005.

17. BOGDUK, N.; GOVIND, J. Cervicogenic headache: an assessment of the evidence on clinical diagnosis, invasive tests, and treatment. The Lancet Neurology, London, v. 8, n. 10, p. 959-968, 2009.

18. FALLA, D. Unravelling the complexity of muscle impairment in chronic neck pain. Manual Therapy, Edinburgh, v. 9, n. 3, p. 125-133, 2004.

19. WATSON, D. H.; TROTT, P. H. Cervical headache: an investigation of natural head posture and upper cervical flexor muscle performance. Cephalalgia, Oslo, v. 13, n. 4, p. 272-284, 1993.

20. BARTON, P. M.; HAYES, K. C. Neck flexor muscle strength, efficiency, and relaxation times in normal subjects and subjects with unilateral neck pain and headache. Archives of Physical Medicine and Rehabilitation, Philadelphia, v. 77, n. 7, p. 680-687, 1996.

21. CAGNIE, B. et al. Differences in isometric neck muscle strength between healthy controls and women with chronic neck pain: The use of a reliable measurement. Archives of Physical Medicine and Rehabilitation, Philadelphia, v. 88, n. 11, p. 1441-1445, 2007.

22. ANDERSEN, L. L. et al. Rapid muscle activation and force capacity in conditions of chronic musculoskeletal pain. Clinical Biomechanics (Bristol, Avon), Bristol, v. 23, n. 10, p. 1237-1242, 2008.

23. O'LEARY, S. et al. Muscle dysfunction in cervical spine pain: Implications for assessment and management. The Journal of Orthopaedic and Sports Physical Therapy, Alexandria, v. 39, n. 5, p. 324-333, 2009.

24. MAROUFI, N.; AHMADI, A.; MOUSAVI KHATIR, S. R. A comparative investigation of flexion relaxation phenomenon in healthy and chronic neck pain subjects. European Spine Journal, Heidelberg, v. 22, n. 1, p. 162-168, 2013.

25. GOGIA, P. P.; SABBAHI, M. A. Electromyographic analysis of neck muscle fatigue in patients with osteoarthritis of the cervical spine. Spine (Phila PA 1976), Hagerstown, v. 19, n. 5, p. 502-506, 1994.

26. ALRICSSON, M. et al. Mobility, muscular strength and endurance in the cervical spine in Swedish Air Force Pilots. Aviation, space, and Environmental Medicine, Washington, v. 72, n. 4, p. 336-342, 2001. 
27. FALLA, D. et al. Myoelectric manifestations of sternocleidomastoid and anterior scalene muscle fatigue in chronic neck pain patients. Clinical Neurophysiology, Amsterdam, v. 114, n. 3, p. 488-495, 2003.

28. FALLA, D. et al. Neck flexor muscle fatigue is side specific in patients with unilateral neck pain. European Journal of Pain, London, v. 8, n. 1, p. 71-77, 2004.

29. REZASOLTAN, A. et al. Preliminary study of neck muscle size and strength measurements in females with chronic non-specific neck pain and healthy control subjects. Manual Therapy, Edinburgh, v. 15, n. 4, p. 400-403, 2010.

30. MADSEN, B. K. et al. Neck and shoulder muscle strength in patients with tensiontype headache: A case-control study. Cephalalgia, Oslo, v. 36, n. 1, p. 29-36, 2016.

31. JULL, G. et al. Cervical musculoskeletal impairment in frequent intermittent headache. Part 1: Subjects with single headaches. Cephalalgia, Oslo, v. 27, n. 7, p. 793-802, 2007.

32. ZITO, G.; JULL, G.; STORY, I. Clinical tests of musculoskeletal dysfunction in the diagnosis of cervicogenic headache. Manual Therapy, Edinburgh, v. 11, n. 2, p. 118-129, 2006.

33. FLORENCIO, L. L. et al. Cervical Muscle Strength and Muscle Coactivation During Isometric Contractions in Patients with Migraine: A Cross-Sectional Study. Headache, St. Louis, v 55, n. 10, p. 1312-1322, 2015.

34. ALPAYCI, M. et al. Decreased neck muscle strength in patients with the loss of cervical lordosis. Clinical Biomechanics (Bristol, Avon), Bristol, v. 33, p. 98102, 2016.

35. PELAIO, B. P. M. Avaliação funcional lombopélvica: comparação entre indivíduos com e sem dor lombar crônica. 2018. 114 p. Tese (Doutorado em Ciências) - Faculdade de Medicina de Ribeirão Preto, Universidade de São Paulo, Ribeirão Preto, 2018.

36. BOKAEE, F. et al. Comparison of isometric force of the craniocervical flexor and extensor muscles between women with and without forward head posture. Cranio, Chattanooga, v. 34, n. 5, p. 286-290, 2016.

37. STRIMPAKOS, N. et al. Intratester and intertester reliability of neck isometric dynamometry. Archives of Physical Medicine and Rehabilitation, Philadelphia, v. 85, n. 8, p. 1309-1316, 2004.

38. VERNON, H.; MIOR, S. The Neck Disability Index: a study of reliability and validity. Journal of Manipulative and Physiological Therapeutics, Lombard, v. 14, n. 7, p. 409-415, 1991.

39. COOK, C. et al. Cross-cultural adaptation and validation of the Brazilian Portuguese version of the Neck Disability Index and Neck Pain and Disability Scale. Spine (Phila PA 1976), Hagerstown, v. 31, n. 14, p. 1621-1627, 2006. 
40. MCCARTHY, M. J. et al. The reliability of the Vernon and Mior neck disability index, and its validity compared with the short form-36 health survey questionnaire. European Spine Journal, Heidelberg, v. 16, n. 12, p. 2111-2117, 2007.

41. CLELAND, J. A.; CHILDS, J. D.; WHITMAN, J. M. Psychometric properties of the Neck Disability Index and Numeric Pain Rating Scale in patients with mechanical neck pain. Archives of Physical Medicine and Rehabilitation, Philadelphia, v. 89, n. 1, p. 69-74, 2008.

42. STEWART, W. F. et al. Development and testing of the Migraine Disability Assessment (MIDAS) Questionnaire to assess headache-related disability. Neurology. Minneapolis, v. 56, n. 6, p. S20-S28, 2001. Supplement 1.

43. STEWART, W. F. et al. Reliability of the migraine disability assessment score in a population-based sample of headache sufferers. Cephalalgia, Oslo, v. 19, n. 2, p. 107-114, 1999.

44. STEWART, W. F. et al. Validity of the Migraine Disability Assessment (MIDAS) score in comparison to a diary-based measure in a population sample of migraine sufferers. Pain, Amsterdam, v. 88, n. 1, p. 41-52, 2000.

45. FLORENCIO, L. L. et al. 12 item Allodynia Symptom Checklist/Brasil: crosscultural adaptation, internal consistency and reproducibility. Arquivos de Neuropsiquiatria, São Paulo, v. 70, n. 11, p. 852-856, 2012.

46. LIPTON, R. B. et al. Cutaneous allodynia in the migraine population. Annals of Neurology, Boston, v. 63, n. 2, p. 148-158, 2008.

47. FALLA, D. et al. Location of innervation zones of sternocleidomastoid and scalene muscles - A basis for clinical and research electromyography applications. Clinical Neurophysiology, Amsterdam, v. 113, n. 1, p. 57-63, 2002.

48. FALLA, D. et al. Muscle pain induces task-dependent changes in cervical agonist/antagonist activity. Journal of Applied Physiology, Bethesda, v. 102, n. 2, p. 601-609, 2007.

49. SENIAM. Recommendations for sensor locations on individual muscles. Disponível em: <http://seniam.org/trapeziusdescendens.html >. Acesso em: 03 jul. 2018.

50. JULL, G. A.; O'LEARY, S. P.; FALLA, D. L. Clinical assessment of the deep cervical flexor muscles: the craniocervical flexion test. Journal of Manipulative and Physiological Therapeutics, Lombard, v. 31, n. 7, p. 525-533, 2008.

51. OKSANEN, A. et al. Force production and EMG activity of neck muscles in adolescent headache. Disability and Rehabilitation, London, v. 30, n. 3, p. 231239, 2008.

52. FERNÁNDEZ-DE-LAS-PEÑAS, C. et al. Cervical muscle co-activation in isometric contractions is enhanced in chronic tension-type headache patients. Cephalalgia, Oslo, v. 28, n. 7, p. 744-751, 2008. 
53. FLORENCIO, L. L. et al. Patients with chronic, but not episodic, migraine display altered activity of their neck extensor muscles. Journal of Electromyography and Kinesiology, New York, v. 30, p. 66-72, 2016.

54. DE LUCA, C. J. The use of surface electromyography in biomechanics. Journal of Applied Biomechanics, Champaign, v. 13, p. 135-163, 1997.

55. HODGES, P. W.; TUCKER, K. Moving differently in pain: A new theory to explain the adaptation to pain. Pain, Amsterdam, v.152, p. S90-S98, 2011. Supplement 3

56. CHIU, T. T.; LAW, E. Y.; CHIU, T. H. Performance of the craniocervical flexion test in subjects with and without chronic neck pain. The Journal of Orthopaedic and Sports Physical Therapy, Alexandria, v. 35, n. 9, p.567-571, 2005.

57. FERNÁNDEZ-DE-LAS-PEÑAS, C. et al. Performance of the craniocervical flexion test, forward head posture, and headache clinical parameters in patients with chronic tension-type headache: a pilot study. The Journal of Orthopaedic and Sports Physical Therapy, Alexandria, v.37, n. 2, p. 33-39, 2007.

58. JULL, G.; KRISTJANSSON, E.; DALL'ALBA, P. Impairment in the cervical flexors: a comparison of whiplash and insidious onset neck pain patients. Manual Therapy, Edinburgh, v. 9, n. 2, p. 89-94, 2004.

59. O'LEARY, S. et al. Cranio-cervical flexor muscle impairment at maximal, moderate, and low loads is a feature of neck pain. Manual Therapy, Edinburgh, v. 12, n. 1, p. 34-39, 2007. 
Anexos

\section{Anexo 1. Neck Disability Index}

Nome:

Data avaliação:

Este questionário foi criado para dar informações ao seu doutor sobre como a sua dor no pescoço tem afetado a sua habilidade para fazer atividades diárias. Por favor responda a cada uma das perguntas e marque em cada seção apenas uma alternativa que melhor se aplique a você.

Seção 1 - Intensidade da dor

Eu não tenho dor nesse momento.

A dor é muito leve nesse momento.

A dor é moderada nesse momento.

A dor é razoavelmente grande nesse momento.

A dor é muito grande nesse momento.

A dor é a pior que se possa imaginar nesse momento.

Seção 2 - Cuidado pessoal (se lavar, se vestir, etc)

Eu posso cuidar de mim mesmo (a) sem aumentar a dor.

Eu posso cuidar de mim mesmo (a) normalmente, mas isso faz aumentar a dor.

É doloroso ter que cuidar de mim mesmo e eu faço isso lentamente e com cuidado.

Eu preciso de ajuda, mas consigo fazer a maior parte do meu cuidado pessoal.

Eu preciso de ajuda todos os dias na maioria dos aspectos relacionados a cuidar de mim mesmo (a).

Eu não me visto, me lavo com dificuldade e fico na cama.

Seção 3 - Levantar coisas

Eu posso levantar objetos pesados sem aumentar a dor.

Eu posso levantar objetos pesados, mas isso faz aumentar a dor.

A dor me impede de levantar objetos pesados do chão, mas eu consigo se eles estiverem colocados em uma boa posição, por exemplo em uma mesa.

A dor me impede de levantar objetos pesados, mas eu consigo levantar objetos com peso entre leve e médio se eles estiverem colocados em uma boa posição.

Eu posso levantar objetos muito leves.

Eu não posso levantar nem carregar absolutamente nada.

Seção 4 - Leitura

$\mathrm{Eu}$ posso ler tanto quanto eu queira sem dor no meu pescoço.

Eu posso ler tanto quanto eu queira com uma dor leve no meu pescoço.

Eu posso ler tanto quanto eu queira com uma dor moderada no meu pescoço.

Eu não posso ler tanto quanto eu queira por causa de uma dor moderada no meu pescoço.

Eu mal posso ler por causa de uma grande dor no meu pescoço.

Eu não posso ler nada.

Pergunta não se aplica por não saber ou não poder ler. 
Seção 5 - Dores de cabeça

Eu não tenho nenhuma dor de cabeça.

Eu tenho pequenas dores de cabeça com pouca frequência.

Eu tenho dores de cabeça moderadas com pouca frequência.

Eu tenho dores de cabeça moderadas muito frequentemente.

Eu tenho dores de cabeça fortes frequentemente.

Eu tenho dores de cabeça quase o tempo inteiro.

Seção 6 - Prestar atenção

Eu consigo prestar atenção quando eu quero sem dificuldade.

Eu consigo prestar atenção quando eu quero com uma dificuldade leve.

Eu tenho uma dificuldade moderada em prestar atenção quando eu quero.

Eu tenho muita dificuldade em prestar atenção quando eu quero.

Eu tenho muitíssima dificuldade em prestar atenção quando eu quero.

Eu não consigo prestar atenção.

Seção 7 - Trabalho

Eu posso trabalhar tanto quanto eu quiser.

Eu só consigo fazer o trabalho que estou acostumado (a) a fazer, mas nada além disso.

Eu consigo fazer a maior parte do trabalho que estou acostumado (a) a fazer, mas nada além disso.

Eu não consigo fazer o trabalho que estou acostumado (a) a fazer.

Eu mal consigo fazer qualquer tipo de trabalho.

Eu não consigo fazer nenhum tipo de trabalho.

Seção 8 - Dirigir automóveis

Eu posso dirigir meu carro sem nenhuma dor no pescoço.

Eu posso dirigir meu carro tanto quanto eu queira com uma dor leve no meu pescoço.

Eu posso dirigir meu carro tanto quanto eu queira com uma dor moderada no meu pescoço.

Eu não posso dirigir o meu carro tanto quanto eu queira por causa de uma dor moderada no meu pescoço.

Eu mal posso dirigir por causa de uma dor forte no meu pescoço.

Eu não posso dirigir meu carro de maneira nenhuma.

Pergunta não se aplica por não saber dirigir ou não dirigir muitas vezes.

Seção 9 - Dormir

Eu não tenho problemas para dormir.

Meu sono é um pouco perturbado (menos de uma hora sem conseguir dormir).

Meu sono é levemente perturbado (1-2 horas sem conseguir dormir).

Meu sono é moderadamente perturbado (2-3 horas sem conseguir dormir).

Meu sono é muito perturbado (3-5 horas sem conseguir dormir).

Meu sono é completamente perturbado (1-2 horas sem sono).

Seção 10 - Diversão 
Eu consigo fazer todas as minhas atividades de diversão sem nenhuma dor no pescoço.

Eu consigo fazer todas as minhas atividades de diversão com alguma dor no pescoço.

Eu consigo fazer a maioria, mas não todas as minhas atividades de diversão por causa da dor no meu pescoço.

Eu consigo fazer poucas das minhas atividades de diversão por causa da dor no meu pescoço.

Eu mal consigo fazer quaisquer atividades de diversão por causa da dor no meu pescoço.

Eu não consigo fazer nenhuma atividade de diversão. 
Anexo 2. Migraine Disability Assessment

\section{QUESTIONÁRIO MIDAS}

As respostas às perguntas abaixo devem considerar todas as dores de cabeça nos últimos 3 meses.

\begin{tabular}{|c|c|}
\hline PERGUNTAS & DIAS \\
\hline Nos últimos 03 meses, & \\
\hline \multicolumn{2}{|l|}{$\begin{array}{l}\text { 1. Quantos dias você perdeu de trabalho ou estudo por causa } \\
\text { de dores de cabeça? }\end{array}$} \\
\hline \multicolumn{2}{|l|}{$\begin{array}{l}\text { 2. Quantos dias a sua produtividade no trabalho ou na escola } \\
\text { reduziu-se pela metade ou menos da metade devido à } \\
\text { dores de cabeça? } \\
\text { (não incluir os dias que você perdeu e já contabilizou na pergunta } \\
\text { anterior) }\end{array}$} \\
\hline $\begin{array}{l}\text { 3. Quantos dias você não realizou afazeres domésticos } \\
\text { (arrumação da casa, compras e cuidados com as crianças) } \\
\text { devido à dores de cabeça? }\end{array}$ & \\
\hline \multicolumn{2}{|l|}{$\begin{array}{l}\text { 4. Quantos dias sua produtividade nos afazeres domésticos } \\
\text { reduziu-se pela metade ou menos da metade devido à } \\
\text { dores de cabeça? } \\
\text { (não inclua os dias que você perdeu e já contabilizou na pergunta } \\
\text { anterior) }\end{array}$} \\
\hline \multicolumn{2}{|l|}{$\begin{array}{l}\text { 5. Quantos dias você não pode participar de atividades } \\
\text { sociais, familiares ou de lazer devido à dor de cabeça? }\end{array}$} \\
\hline \multicolumn{2}{|l|}{ TOTAL (itens 1 a 5) } \\
\hline \multicolumn{2}{|l|}{$\begin{array}{l}\text { Quantos dias você teve de dor de cabeça nos últimos } 3 \text { meses? } \\
\text { (Caso a dor de cabeça tenha durado mais de um dia, conte cada um dos } \\
\text { dias que durou.) }\end{array}$} \\
\hline $\begin{array}{l}\text { Numa escala de } 0 \text { a } 10 \text {, em média, qual a intensidade de suas dores } \\
\text { de cabeça? (onde } 0=\text { nenhuma dor e } 10=\text { a dor mais intensa) }\end{array}$ & \\
\hline
\end{tabular}

\section{RESULTADO:}

\begin{tabular}{r|l}
\hline PONTOS & GRAU / INCAPACIDADE \\
\hline 0 a 5 & GRAU I (incapacidade mínima ou nenhuma) \\
6 a 10 & GRAU II (incapacidade leve) \\
11 a 20 & GRAU III (incapacidade moderada) \\
$>20$ & GRAU IV (incapacidade severa) \\
\hline
\end{tabular}




\section{Anexo 3. 12- item Allodynia Symptom Checklist}

Nome:

RG.:

Data:

\begin{tabular}{|c|c|c|c|c|c|}
\hline $\begin{array}{l}\text { 1. Durante sua dor de cabeça mais forte, você sente incômodo ao pentear ou } \\
\text { escovar seu cabelo? }\end{array}$ & $\begin{array}{c}(\text { ) } \\
\text { Essa situação não } \\
\text { se aplica a mim }\end{array}$ & $\begin{array}{r}(1) \\
\text { Não, } \\
\text { nunca }\end{array}$ & $\underset{\text { Raramente }}{()}$ & $\begin{array}{l}(\quad) \\
\text { Às vezes sim, } \\
\text { Às vezes não }\end{array}$ & $\begin{array}{c}(1) \\
\text { A maior parte } \\
\text { das vezes }\end{array}$ \\
\hline $\begin{array}{l}\text { 2. Durante sua dor de cabeça mais forte, você sente incômodo ao prender seu } \\
\text { cabelo (por exemplo, rabo de cavalo)? }\end{array}$ & $\begin{array}{c}(\quad) \\
\text { Essa situação não } \\
\text { se aplica a mim }\end{array}$ & $\begin{array}{r}(\text { ) } \\
\text { Não, } \\
\text { nunca }\end{array}$ & $\begin{array}{c}(\quad) \\
\text { Raramente }\end{array}$ & $\begin{array}{l}(\quad) \\
\text { Às vezes sim, } \\
\text { Às vezes não }\end{array}$ & $\begin{array}{c}(\quad) \\
\text { A maior parte } \\
\text { das vezes }\end{array}$ \\
\hline 3. Durante sua dor de cabeça mais forte, você sente incômodo ao fazer a barba? & $\begin{array}{l}\text { ( ) } \\
\text { Essa situação não } \\
\text { se aplica a mim }\end{array}$ & $\begin{array}{r}(\quad) \\
\text { Não, } \\
\text { nunca }\end{array}$ & $\begin{array}{c}(\quad) \\
\text { Raramente }\end{array}$ & $\begin{array}{l}\quad(\quad) \\
\text { Às vezes sim, } \\
\text { Às vezes não }\end{array}$ & $\begin{array}{l}(\quad) \\
\text { A maior parte } \\
\text { das vezes }\end{array}$ \\
\hline 4. Durante sua dor de cabeça mais forte, você sente incômodo ao usar óculos? & $\begin{array}{c}\text { ( ) } \\
\text { Essa situação não } \\
\text { se aplica a mim }\end{array}$ & $\begin{array}{r}(\quad) \\
\text { Não, } \\
\text { nunca }\end{array}$ & $\begin{array}{c}(\quad) \\
\text { Raramente }\end{array}$ & $\begin{array}{l}\quad(\quad) \\
\text { Às vezes sim, } \\
\text { Às vezes não }\end{array}$ & $\begin{array}{c}(\quad) \\
\text { A maior parte } \\
\text { das vezes }\end{array}$ \\
\hline $\begin{array}{l}\text { 5. Durante sua dor de cabeça mais forte, você sente incômodo ao usar lentes de } \\
\text { contato? }\end{array}$ & $\begin{array}{c}\text { ( ) } \\
\text { Essa situação não } \\
\text { se aplica a mim }\end{array}$ & $\begin{array}{r}(\quad) \\
\text { Não, } \\
\text { nunca }\end{array}$ & $\begin{array}{c}(\quad) \\
\text { Raramente }\end{array}$ & $\begin{array}{c}\quad(\quad) \\
\text { Às vezes sim, } \\
\text { Às vezes não }\end{array}$ & $\begin{array}{c}(\quad) \\
\text { A maior parte } \\
\text { das vezes }\end{array}$ \\
\hline 6. Durante sua dor de cabeça mais forte, você sente incômodo ao usar brincos? & $\begin{array}{c}\text { ( ) } \\
\text { Essa situação não } \\
\text { se aplica a mim }\end{array}$ & $\begin{array}{r}\left(\begin{array}{c}() \\
\text { Não, } \\
\text { nunca }\end{array}\right. \\
\end{array}$ & $\begin{array}{c}(\quad) \\
\text { Raramente }\end{array}$ & $\begin{array}{l}\quad(\quad) \\
\text { Às vezes sim, } \\
\text { Às vezes não }\end{array}$ & $\begin{array}{c}(\quad) \\
\text { A maior parte } \\
\text { das vezes }\end{array}$ \\
\hline 7. Durante sua dor de cabeça mais forte, você sente incômodo ao usar colar? & $\begin{array}{c}(\quad) \\
\text { Essa situação não } \\
\text { se aplica a mim }\end{array}$ & $\begin{array}{l}\left(\begin{array}{c}() \\
\text { Não, } \\
\text { nunca }\end{array}\right. \\
\end{array}$ & $\begin{array}{c}(\quad) \\
\text { Raramente }\end{array}$ & $\begin{array}{c}(\quad) \\
\text { Às vezes sim, } \\
\text { Às vezes não }\end{array}$ & $\begin{array}{c}() \\
\text { A maior parte } \\
\text { das vezes }\end{array}$ \\
\hline $\begin{array}{l}\text { 8. Durante sua dor de cabeça mais forte, você sente incômodo ao usar roupas } \\
\text { justas? }\end{array}$ & $\begin{array}{c}(\text { ) } \\
\text { Essa situação não } \\
\text { se aplica a mim }\end{array}$ & $\begin{array}{r}\left(\begin{array}{l}\text { ( } \\
\text { Não, } \\
\text { nunca }\end{array}\right. \\
\end{array}$ & $\begin{array}{c}(\quad) \\
\text { Raramente }\end{array}$ & $\begin{array}{l}(\quad) \\
\text { Às vezes sim, } \\
\text { Às vezes não }\end{array}$ & $\begin{array}{c}() \\
\text { A maior parte } \\
\text { das vezes }\end{array}$ \\
\hline $\begin{array}{l}\text { 9. Durante sua dor de cabeça mais forte, você sente incômodo ao tomar banho } \\
\text { (por exemplo, quando a água do chuveiro cai no seu rosto)? }\end{array}$ & $\begin{array}{c}(\text { ) } \\
\text { Essa situação não } \\
\text { se aplica a mim }\end{array}$ & $\begin{array}{r}(\quad) \\
\text { Não, } \\
\text { nunca }\end{array}$ & $\begin{array}{c}(\quad) \\
\text { Raramente }\end{array}$ & $\begin{array}{l}(\quad) \\
\text { Às vezes sim, } \\
\text { Às vezes não }\end{array}$ & $\begin{array}{c}(1) \\
\text { A maior parte } \\
\text { das vezes }\end{array}$ \\
\hline $\begin{array}{l}\text { 10. Durante sua dor de cabeça mais forte, você sente incômodo ao apoiar seu } \\
\text { rosto ou cabeça em um travesseiro ou almofada? }\end{array}$ & $\begin{array}{c}(\quad) \\
\text { Essa situação não } \\
\text { se aplica a mim }\end{array}$ & $\begin{array}{r}(\text { ) } \\
\text { Não, } \\
\text { nunca }\end{array}$ & $\begin{array}{c}(\quad) \\
\text { Raramente }\end{array}$ & $\begin{array}{l}\quad(\quad) \\
\text { Às vezes sim, } \\
\text { Às vezes não }\end{array}$ & $\begin{array}{l}(\quad) \\
\text { A maior parte } \\
\text { das vezes }\end{array}$ \\
\hline $\begin{array}{l}\text { 11. Durante sua dor de cabeça mais forte, você sente incômodo ao se expor ao } \\
\text { calor (por exemplo, cozinhar, lavar seu rosto com água quente)? }\end{array}$ & $\begin{array}{c}\text { ( ) } \\
\text { Essa situação não } \\
\text { se aplica a mim }\end{array}$ & 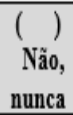 & $\begin{array}{c}(\quad) \\
\text { Raramente }\end{array}$ & $\begin{array}{l}(\quad) \\
\text { Às vezes sim, } \\
\text { Às vezes não }\end{array}$ & $\begin{array}{c}(\quad) \\
\text { A maior parte } \\
\text { das vezes }\end{array}$ \\
\hline $\begin{array}{l}\text { 12. Durante sua dor de cabeça mais forte, você sente incômodo ao se expor ao } \\
\text { frio (por exemplo, usar uma bolsa de gelo, lavar seu rosto com água fria)? }\end{array}$ & $\begin{array}{c}(\text { ) } \\
\text { Essa situação não } \\
\text { se aplica a mim }\end{array}$ & $\begin{array}{r}(\text { ) } \\
\text { Não, } \\
\text { nunca }\end{array}$ & $\begin{array}{l}(\text { ) } \\
\text { Raramente }\end{array}$ & $\begin{array}{l}(\quad) \\
\text { Às vezes sim, } \\
\text { Às vezes não }\end{array}$ & $\begin{array}{c}(\quad) \\
\text { A maior parte } \\
\text { das vezes }\end{array}$ \\
\hline \multicolumn{6}{|l|}{ Pontuação total } \\
\hline Some & & & & & \\
\hline
\end{tabular}




\section{Anexo 4. Documento comprobatório de aprovação no Comitê de Ética}

HOSPITAL DAS CLINICAS DA FACULDADE DE MEDICINA DE RIBEIRÃO PRETO DA UNIVERSIDADE DE SÃO PAULO
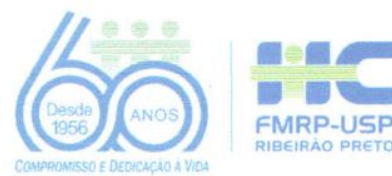

Ribeirão Preto, 03 de agosto de 2016

Oficio $n^{\circ} 2663 / 2016$

$\mathrm{CEP} / \mathrm{MGV}$

Prezadas Senhoras,

O trabalho intitulado "RAZÃO DA FORÇA MUSCULAR E ELETROMIOGRÁFICA DOS MÚSCULOS EXTENSORES E FLEXORES CERVICAIS EM INDIVIDUOS COM MIGRÂNEA - UM ESTUDO TRANSVERSAL" - Versão 2, de 01/07/2016, foi analisado pelo Comitê de Ética em Pesquisa em sua $433^{2}$ Reunião Ordinária, realizada em 01/08/2016 e enquadrado na categoria: APROVADO, bem como o Termo de Consentimento Livre e Esclarecido - Versão 2, de 01/07/2016, de acordo com o Processo HCRP n 6861/2016.

De acordo com Carta Circular $n^{\circ} 003 / 2011 / C O N E P / C N S$, datada de 21/03/2011, o sujeito de pesquisa ou seu representante, quando for o caso, deverá rubricar todas as folhas do Termo de Consentimento Livre e Esclarecido TCLE - apondo sua assinatura na última do referido Termo; o pesquisador responsável deverá da mesma forma, rubricar todas as folhas do Termo de Consentimento Livre e Esclarecido - TCLE - apondo sua assinatura na última página do referido Termo.

Este Comitê segue integralmente a Conferência Internacional de Harmonização de Boas Práticas Clínicas (IGH-GCP), bem como a Resolução no 466/ 12 CNS/MS

Lembramos que devem 'ser apresentados a este CEP, o Relatório Parcial e o Relatório Final da pesquisa.

Atenciosamente.

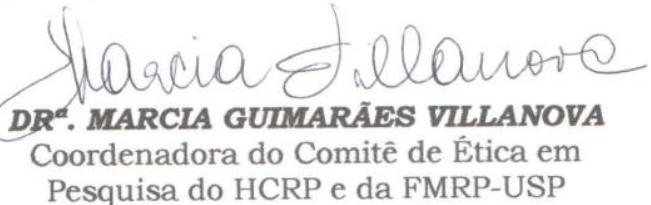

Ilustríssimas Senhoras

MARIANA TEDESCHI BENATTO

PROF ${ }^{2}$.DR ${ }^{\text {a }}$.DÉBORA BEVILAQUA GROSSI(Orientadora)

Depto. de Biomecânica, Medicina e Reabilitação do Aparelho Locomotor

HOSPITAL DAS CLINICAS DA FACULDADE DE MEDICINA DE RIBEIRÃO PRETO DA UNIVERSIDADE DE SÃO PAULO Campus Universitário - Monte Alegre Comitê de Ética em Pesquisa do HCRP e FMRP-USP 14048-900 Ribeirão Preto SP FWA-00002733; IRB-00002186 e
Registro Plataforma Brasil /CONEP $n^{\circ} 5440$ (016) $3602-2228$ (016) $3602-2228$
cep@hcrp.usp.br 


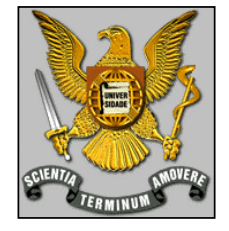

FACULDADE DE MEDICINA DE RIBEIRÃO PRETO UNIVERSIDADE DE SÃO PAULO

DEPARTAMENTO DE BIOMECÂNICA, MEDICINA E

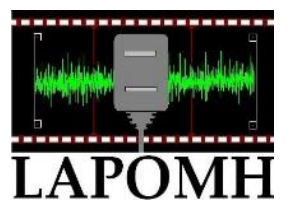
REABILITAÇÃO DO APARELHO LOCOMOTOR

LAPOMH - Laboratório de Análise da Postura e do Movimento Humano

Título do Projeto: "Razão da força muscular e eletromiográfica dos músculos extensores e flexores cervicais em indivíduos com migrânea - um estudo transversal"

Pesquisadores Responsáveis: Mariana Tedeschi Benatto (16) 98806-6096 - mariana.benatto@gmail.com

Profa. Dra. Débora Bevilaqua Grossi

Pesquisadores Colaboradores: Profa. Dra. Fabiola Dach, Ms. Carina Ferreira Pinheiro, Ms. Lidiane Lima Florêncio, Ft Samuel S. Lodovichi

O (a) Sr. (a) está sendo convidado (a) a participar de um estudo que tem como objetivo verificar a força dos músculos do seu pescoço por causa da sua enxaqueca.

Na primeira etapa do estudo, que dura entre 20 a 30 minutos, o Sr. (a) responderá a 6 questionários sobre dados pessoais (idade, escolaridade, presença de dor de cabeça e no pescoço), o quanto sua dor no pescoço atrapalha suas atividades, sobre quantos dias você tem de dor cabeça e quão forte ela é para limitar suas idas ao trabalho ou suas atividades em casa, perguntas para saber se o (a) Sr. (a) tem medo de realizar movimentos, listar 3 atividades do dia-a-dia que te incomodam por causa da sua dor de cabeça e o último, ver o quanto sua dor de cabeça provoca sensibilidade em partes do seu corpo, como couro cabeludo.

Após responder os questionários, iniciaremos a avaliação do movimento do pescoço e da força, e todas as etapas desta avaliação ocorrerão no Laboratório de Análise da Postura e do Movimento Humano - LAPOMH, localizado no prédio da Fisioterapia, no campus de Ribeirão Preto da Universidade de São Paulo. Essa avaliação terá duração máxima de 01 hora e 30 minutos.

Inicialmente serão colocadas algumas plaquinhas no pescoço do (a) Sr. (a) para verificarmos como seu músculo funciona. Para não ocorrer interferências, os pelos serão raspados com uma lâmina de barbear descartável. Todo o procedimento será feito por um profissional habilitado, e em caso de o (a) Sr. (a) sentir dor ou desconforto durante essa avaliação, o teste será interrompido.

Deitado de barriga para cima, será colocado um aparelho semelhante ao de aferir pressão embaixo do seu pescoço e o (a) Sr. (a) deverá dobrar o pescoço, devagar, para frente e manter essa posição por 10 segundos e repetirá o movimento 5 vezes. Ainda de barriga para cima, o fisioterapeuta irá prender alguns pontos do corpo do (a) Sr. (a) com 
fitas e pedirá que seja realizado o movimento de dobrar o pescoço para frente. Para medir o quanto de força o (a) Sr. (a) está fazendo, um aparelho será posicionado na testa do (a) Sr. (a). Em seguida, o (a) Sr. (a) deitará de barriga para baixo e fará o movimento de levantar a cabeça. Será utilizado o mesmo aparelho para medir a força, mas agora o aparelho será posicionada na parte de trás da cabeça. No último teste o (a) Sr. (a) terá que permanecer com a cabeça desgruadada da maca, primeiro com a barriga para cima e depois com a barriga para baixo. Para termos certeza de que o (a) Sr. (a) está mantendo a cabeça no lugar um fio com um pesinho será amarrado na cabeça do (a) Sr. (a). Caso esse peso encoste no chão, o teste termina.

Somente os pesquisadores responsáveis terão acesso às informações obtidas. $\mathrm{O}$ (a) Sr. (a) não receberá nenhum benefício direto pela participação da pesquisa. No entanto, esperamos que os resultados do estudo nos ajude a entender melhor as repercussões musculares e propor melhoras no tratamento para pacientes com enxaqueca. Sua participação não é obrigatória. Pela sua participação, o (a) Sr. (a) não receberá nenhum tipo de seguro de vida ou saúde que possa beneficiá-lo (a). Caso não queira participar ou deseje sair do estudo, você não receberá punição alguma e isso não influenciará seu tratamento no Ambulatório de Cefaleia e Algias Craniofaciais do Hospital das Clínicas da Faculdade de Medicina de Ribeirão Preto da Universidade de São Paulo.

Este documento possui duas vias iguais. Caso o (a) Sr. (a) aceite participar, as duas vias serão assinadas e rubricadas pelo (a) Sr. (a) e pelo pesquisador responsável em todas as páginas, uma via será entregue ao (a) Sr. (a) e a outra ficará com o pesquisador responsável.

Eventuais dúvidas sobre os aspectos éticos relacionados à essa pesquisa devem ser elucidadas junto ao Comitê de Ética em Pesquisa do Hospital das Clínicas da Faculdade de Medicina de Ribeirão Preto, através do número (16) 3602-2228 ou ainda com o pesquisador responsável, Mariana Tedeschi Benatto, pelo número (16) 988066096.

Nome do participante:

Assinatura do participante:

Data:

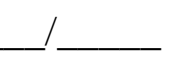

Pesquisador

responsável:

Assinatura do pesquisador responsável:

Data: 


\section{Apêndices}

\section{Apêndice 1. Ficha de triagem}

Data: ___ I _ _

Nome:

Reg.HC

Idade: Estado Civil:

Profissão: Escolaridade:

Peso: Altura: IMC:

Cidade:

ANAMNESE

Diagnóstico:

Doenças Associadas:

Medicamentos em uso:

História de trauma em MMII? ( ) NÃO ( ) SIM.

Local:

Tempo:

História de trauma na face ou pescoço? ( ) NÃO ( ) SIM.

Local:

Tempo:

Já realizou tratamento fisioterapêutico para a região da face ou pescoço? ( ) NÃO ( ) SIM

Presença de vestibulopatia (labirintite): ( ) NÃO ( ) SIM

Presença de tontura? ( ) NÃO ( ) SIM - Fora da crise: ( ) NÃO ( ) SIM

Sintomas: ( ) vertigem (rotatória)

( ) Outro:

\section{CEFALEIA}

Cefaleia nos últimos 3 meses? ( ) NÃO ( ) SIM - Aura? ( ) NÃO ( ) SIM

Data da última crise:

Dias de dor/mês: Duração das crises/horas: Anos de cefaleia:

Intensidade da dor: 
$\begin{array}{lllllllllllll}\text { Sem dor } & 0 & 1 & 2 & 3 & 4 & 5 & 6 & 7 & 8 & 9 & 10 & \text { dor máxima }\end{array}$ Localização da dor: ( ) Hemicraniana ( ) Holocraniana ( ) Frontal
( ) Temporal
( ) Occiptal
( ) Outro:

Dor na avaliação (0-10):

\section{CERVICALGIA}

( ) NÃO ( ) SIM Há quanto tempo:

Intensidade de dor:

$\begin{array}{lllllllllllll}\text { Sem dor } & 0 & 1 & 2 & 3 & 4 & 5 & 6 & 7 & 8 & 9 & 10 & \text { dor máxima }\end{array}$

Dor na avaliação (0-10): 
Apêndice 2. Amplitude do RMS bruto dos músculos flexores e extensores durante a CIVM em microvolts $(\mu \mathrm{V})$.

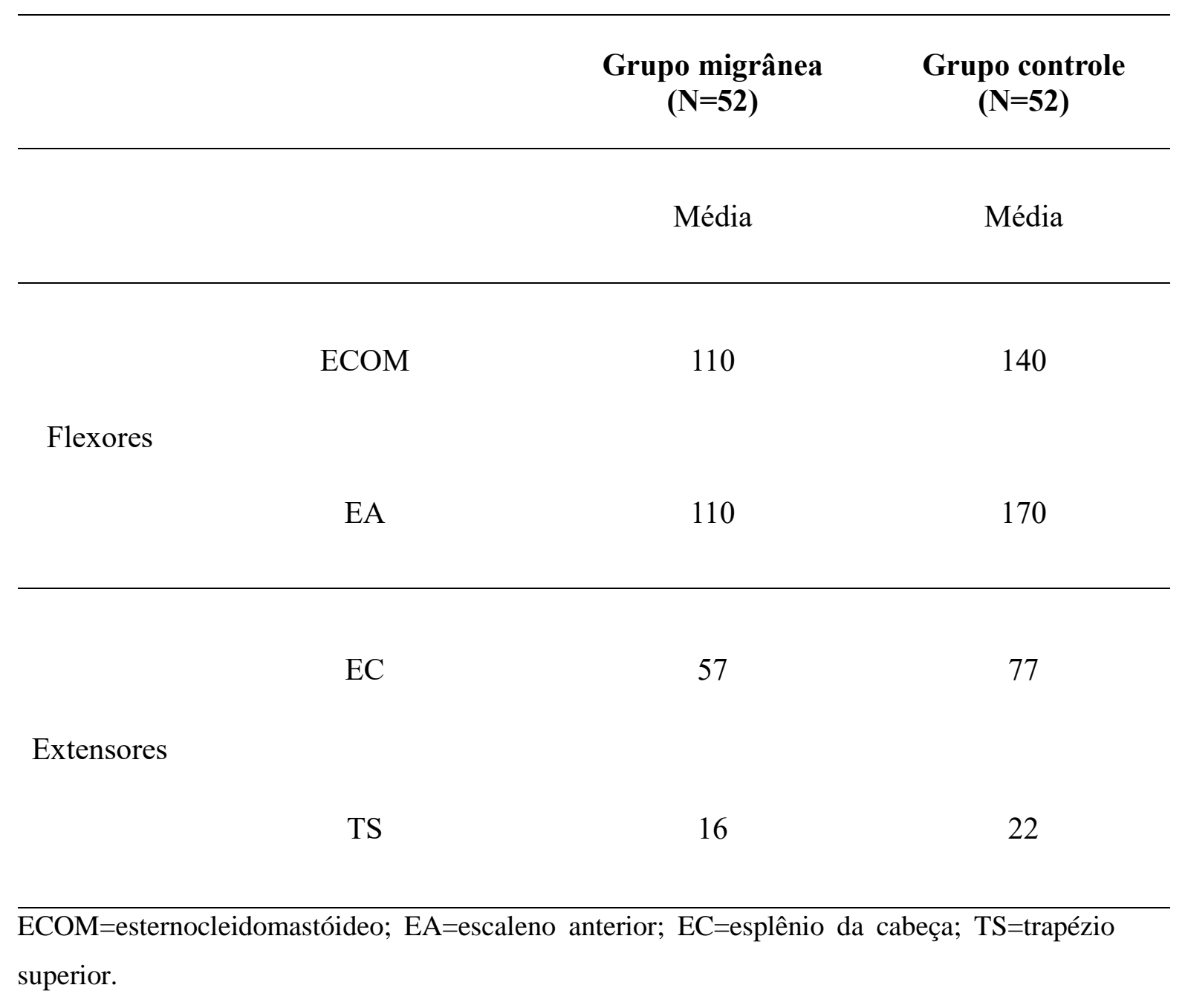

